\title{
Latitudinal extension of low-latitude scintillations measured with a network of GPS receivers
}

\author{
C. E. Valladares ${ }^{1}$, J. Villalobos ${ }^{2}$, R. Sheehan ${ }^{1}$, and M. P. Hagan ${ }^{1}$ \\ ${ }^{1}$ Institute for Scientific Research, Boston College, Newton Center, Massachusetts, USA \\ ${ }^{2}$ Department of Physics, Universidad Nacional de Colombia, Bogota, Colombia
}

Received: 1 December 2003 - Revised: 8 April 2004 - Accepted: 12 May 2004 - Published: 23 September 2004

Part of Special Issue "Equatorial and low latitude aeronomy"

\begin{abstract}
A latitudinal-distributed network of GPS receivers has been operating within Colombia, Peru and Chile with sufficient latitudinal span to measure the absolute total electron content (TEC) at both crests of the equatorial anomaly. The network also provides the latitudinal extension of GPS scintillations and TEC depletions. The GPS-based information has been supplemented with density profiles collected with the Jicamarca digisonde and JULIA power maps to investigate the background conditions of the nighttime ionosphere that prevail during the formation and the persistence of plasma depletions. This paper presents case-study events in which the latitudinal extension of GPS scintillations, the maximum latitude of TEC depletion detections, and the altitude extension of radar plumes are correlated with the location and extension of the equatorial anomaly. Then it shows the combined statistics of GPS scintillations, TEC depletions, TEC latitudinal profiles, and bottomside density profiles collected between September 2001 and June 2002. It is demonstrated that multiple sights of TEC depletions from different stations can be used to estimate the drift of the background plasma, the tilt of the plasma plumes, and in some cases even the approximate time and location of the depletion onset. This study corroborates the fact that TEC depletions and radar plumes coincide with intense levels of GPS scintillations. Bottomside radar traces do not seem to be associated with GPS scintillations. It is demonstrated that scintillations/depletions can occur when the TEC latitude profiles

tions/TEC depletions mainly occur when the altitude of the magnetic equator F-region is above $500 \mathrm{~km}$. Nevertheless, in many instances GPS scintillations and TEC depletions are observed to exist when the F-layer is well below $500 \mathrm{~km}$ or to persist when the F-layer undergoes its typical nighttime descent. Close inspection of the TEC profiles during scintillations/depletions events that occur when the equatorial F-layer peak is below $500 \mathrm{~km}$ altitude reveals that on these occasions the ratio of the crest-to-equator TEC is above 2 , and the crests are displaced $10^{\circ}$ or more from the magnetic equator. When the equatorial F-layer is above $500 \mathrm{~km}$, neither of the two requirements is needed, as the flux tube seems to be inherently unstable. We discuss these findings in terms of the RayleighTaylor instability (RTI) mechanism for flux-tube integrated quantities. We advance the idea that the seeming control that the reverse fountain effect exerts on inhibiting or suppressing GPS scintillations may be related to the redistribution of the density and plasma transport from the crests of the anomaly toward the equatorial region and then to much lower altitudes, and the simultaneous decrease of the F-region altitude. These two effects originate a decrease in the crest/trough ratio and a reduction of the crests separation, making the whole flux tube more stable to the RTI. The correspondence between crest separation, altitude of the equatorial F-region, the onset of depletions, and the altitude (latitude) extension of plumes (GPS scintillations) can be used to track the fate of the density structures.
\end{abstract} are symmetric, asymmetric or highly asymmetric; this is during the absence of one crest. Comparison of the location of the northern crest of the equatorial anomaly and the maximum latitude of scintillations reveals that for $90 \%$ of the days, scintillations are confined within the boundaries of the $50 \%$ decay limit of the anomaly crests. The crests of the anomaly are the regions where the most intense GPS scintillations and the deepest TEC depletions are encountered. In accord with early results, we observe that GPS scintilla-

Correspondence to: C. E. Valladares

(valladar@bc.edu)
Key words. Ionosphere (Equatorial ionsphere; ionospheric irregularities; modeling and forecasting)

\section{Introduction}

Equatorial spread $\mathrm{F}$ (ESF) is a complex plasma phenomenon that develops almost exclusively during the nighttime hours. ESF consists of a turbulent gravitational overturn of the ionosphere in which plasma densities and electric fields develop irregular structures with scale lengths from hundreds 
of kilometers down to sub-meter sizes. A basic understanding of ESF has been obtained due to insights from Jicamarca measurements (Woodman and LaHoz, 1976), satellite in-situ observations (McClure et al., 1977), and numerical modeling of the Rayleigh-Taylor instability (Ossakov et al., 1979; Zalesak and Ossakov, 1980). Woodman and LaHoz (1976), almost 3 decades ago, presented two-dimensional maps of coherent echoes to indicate that plume-like structures extend for hundreds of kilometers in altitude, connecting the unstable bottomside F-region with the spread F on the stable topside. The radar maps provided strong evidence for a plasma density depletion convecting upward, following a RaleighTaylor Instability (RTI) mechanism. McClure et al. (1977) used plasma composition measured by the RPA on board the AE-C satellite to demonstrate that the plasma biteouts or depletions, seen in the nighttime equatorial F-region, sometimes contained molecular ions. This fact implied that the plasma depletions had recently moved from the low bottomside. Numerical calculations of the RTI conducted by Ott (1978) provided the rising velocity of the plasma bubbles in the collisional and inertial regimes, well in accord with experimental values. Computer simulations of the nonlinear collisional RTI carried out by Ossakov et al. (1979) demonstrated the production of topside irregularities by the rising bubbles and the dependence of the instability growth rate on the altitude of the F-layer and the gradient scale-size. Zalesak et al. (1982) incorporated the zonal neutral wind and an underlying E-region conductivity in their simulations and were able to demonstrate that these processes produce a slow-down effect in the evolution of ESF. Satyanarayana et al. (1984) investigated the effect of a velocity shear in the RTI that tends to stabilize the small-scale irregularities and excite long wavelength modes. Zargham and Seyler (1987) used boundary conditions proper for the nighttime F-layer to show the inherently anisotropic state of the generalized RTI. According to their numerical results, they postulated that a predominant $\mathrm{km}$-scale wavelength develops in the zonal direction for an eastward-directed effective electric field, and shocklike structures are formed along the vertical direction.

It is well accepted that near sunset, the dynamics of the equatorial ionosphere are dominated by the pre-reversal enhancement (PRE) (Woodman, 1970) of the vertical drift, and that the variability of this process may dictate the onset or not of ESF (Basu et al., 1996; Fejer et al., 1999; Hysell and Burcham, 1998). The rapid decay of the E-region conductivity produces polarization electric fields that vary greatly in local time and latitude. The PRE is originated by a response of the electric fields to maintain a curl-free nature near sunset (Eccles, 1998), but is modified, up to some extent, by the divergence of zonal Hall currents in the off-equatorial Eregion (Farley et al., 1986) and/or the zonal Cowling conductivity gradients in the electrojet (Haerendel and Eccles, 1992). The maximum value of the PRE has been associated with the generation and evolution of ESF (Fejer et al., 1999). These authors found that during solar minimum conditions a PRE larger than $15-20 \mathrm{~m} / \mathrm{s}$ implied the occurrence of radar plumes extending to the topside. During so- lar maximum conditions, (>200) a PRE of $40-45 \mathrm{~m} / \mathrm{s}$ was required for the generation of ESF. When the PRE is fully developed, the Appleton anomaly is seen to re-intensify after sunset, making the crests more prominent and displaced even further away $\left(15^{\circ}-20^{\circ}\right)$ from the magnetic equator. This close relationship between vertical drifts, the location of the crests of the anomaly, and ESF has been noted by several researchers (Whalen, 2001; Valladares et al., 2001). Others have used the amplitude of the equatorial anomaly to define precursors of the occurrence of ESF (Raghavarao et al., 1988; Sridharan et al., 1994). Whalen (2001) used bottomside densities collected by a network of sounders that operated in September 1958 to demonstrate that strong bottomside spread F (BSSF) and bubbles occurred when the crest density exceeded $3.5 \times 10^{6} \mathrm{~cm}^{-3}$, and the anomaly peak was located poleward of $15.4^{\circ}$ dip latitude. Weaker BSSF was observed when the crest of the anomaly was smaller and closer to the equator. No BSSF was detected when the peak density was below $3.5 \times 10^{6} \mathrm{~cm}^{-3}$ or if the crest was non-existent. Valladares et al. (2001) used TEC values measured with 6 GPS receivers forming a latitudinal chain, to show that during the equinoxes a crest-to-trough ratio equal to 2 or larger always implied the onset of UHF scintillations and the presence of radar plumes in the JULIA maps.

In addition to the vertical drift and the altitude of the F-layer, a downward vertical wind makes the F-region unstable to the initiation of the RTI. The meridional wind can also influence the onset of irregularities, by making the F-region more stable and inhibiting ESF. Maruyama and Matura (1984) and Maruyama (1988) indicated that a transequatorial wind could depress the F-layer in the lee side hemisphere, changing the field-integrated Pedersen conductivity and, consequently, suppressing the growth of the RTI. Mendillo et al. (1992) presented measurements from the Altair incoherent scatter radar and all-sky optical images providing evidence that a southward wind was somewhat responsible for lowering the density contours and making the whole flux tube more stable to the onset of the RTI. More recently, Mendillo et al. (2001) have re-examined the importance of the meridional winds in suppressing ESF during a campaign in South America. These researchers concluded that during the eight days of the campaign in September 1998, the meridional wind did not influence the onset of ESF in the pre-midnight hours. However, Devasia et al. (2002) have presented evidence that suggests that when $h^{\prime} \mathrm{F}$ is below $300 \mathrm{~km}$, ESF may occur only for a thermospheric meridional wind directed equatorward and less than $60 \mathrm{~m} / \mathrm{s}$.

In spite of this formidable advance in the theory of ESF, we are not able to forecast with complete certainty the dayto-day variability of ESF, even less to predict the specific region that will become unstable or calculate in advance the maximum altitude that the plasma bubbles may attain. This apparent failure may be a sign of our inability to measure the great variability of several ionospheric parameters with the accuracy that is needed. Alternatively, it may indicate that one important ingredient of the physics of equatorial plasma bubbles is still missing. 
This paper shows TEC values measured by a network of ten GPS receivers during ten months, spanning September 2001 and June 2002. We present GPS scintillations measured by three of these receivers in an effort to assess the latitudinal (and apex altitude) extension of the plasma bubbles. We also used information of TEC depletions, and range-time maps of coherent echoes collected with the JULIA radar, to indicate the spatial location of plasma biteouts and to infer that the GPS scintillations, in fact, correspond to plasma bubbles or depletions in the equatorial F-region. We also investigate the background conditions of the equatorial ionosphere, by providing the location of the crests and the trough. Three events are analyzed in detail and the statistics of the first 10 months of operations at Bogota are introduced to demonstrate that in most cases the plasma bubbles extend up to the poleward edges of the anomaly. Finally, we use measurements conducted with the Jicamarca digisonde to corroborate the relationship between the appearance of GPS scintillations and the altitude of the F-region.

\section{Instrumentation}

TEC measurements were gathered using 10 GPS receivers located near the west coast of South America, and spanning in latitude between $9^{\circ} \mathrm{N}$ and $40^{\circ} \mathrm{S}$. Their fields-of-view are indicated in Fig. 1, using circles extending $45^{\circ}$ in elevation. Five of these receivers are managed by BC. These receivers have been implemented with specially-designed software that makes real-time calculations of the amplitude scintillations. Four of the sites (Bogota, Iquitos, Pucallpa and Cuzco) are equipped with CRS1000 Leica receivers running at $10 \mathrm{~Hz}$. The last of the five sites (Ancon) possesses two GPS receivers, a Novatel that records GPS signals at $50 \mathrm{~Hz}$, and an Ashtech receiver dedicated to measure TEC values. Figure 1 also displays the geographic location of the magnetic equator and the $15^{\circ}$ magnetic latitude line. Note that the Bogota and Santiago stations are practically conjugate from the magnetic equator. These two receivers are able to measure, quite frequently, the TEC value in the northern and southern crests of the anomaly. Other systems, such as the UHF ( $\sim 250 \mathrm{MHz})$ and L-band scintillation receivers, have operated at Ancon and Antofagasta since 1994 and 1996, respectively. These systems measure the S4 index, the spectra of the amplitude scintillation, and the zonal drift of the irregularities (Valladares et al., 1996), using the space-antenna technique. The ionospheric penetration points corresponding to the UHF systems are shown with the large crosses, and labeled F7 and F8. These points are the 350-km altitude intersection of the lines-of-sight directed to 2 geosynchronous satellites parked at the $100^{\circ} \mathrm{W}$ and $23^{\circ} \mathrm{W}$ meridians. A ground projection of the magnetic field line passing above the Ancon F8 ionospheric intersection has been traced to indicate that this point and the Antofagasta F7 intersection point are almost aligned along the same field line. The apex altitude of this field line is at $1200 \mathrm{~km}$ over the magnetic equator and is displayed ending in the F-region $(350 \mathrm{~km})$ near

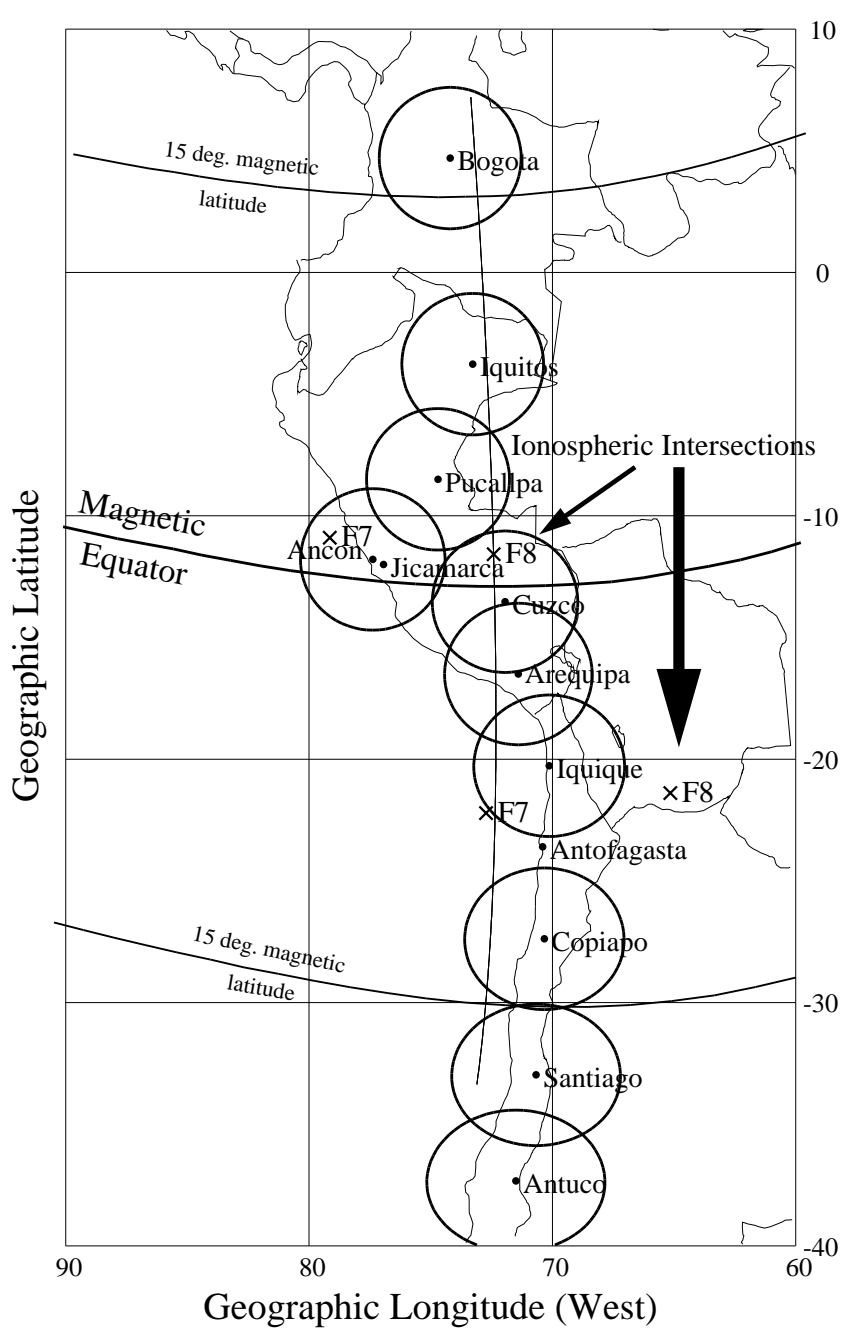

Fig. 1. Geographic locations of several GPS receivers operating near the west coast of South America. The stations at Ancon, Cuzco, Pucallpa, Iquitos and Bogota form the North Andes Project (NAP) network. The stations at Iquique, Copiapo and Antuco are part of the South Andes Project (SAP) network. The stations at Arequipa and Santiago correspond to the IGS network of receivers. The locations of the Jicamarca radar and the sub-ionospheric intersections of the lines-of-sight from the Ancon and Antofagasta UHF receivers to the F7 and F8 satellites are also included. The line crossing the F8 intersection point shows the ground projection of a field line with apex height equal to $1200 \mathrm{~km}$ that ends at $350 \mathrm{~km}$ altitude.

Bogota in the north and close to Santiago in the south. This paper also presents altitude-time maps of coherent echoes collected with the JULIA radar. A comprehensive description of this system can be found in the publication by Hysell and Burcham (1998).

\section{TEC depletions}

A TEC depletion consists of a sudden reduction of TEC followed by a recovery to a level near the TEC value preceding 

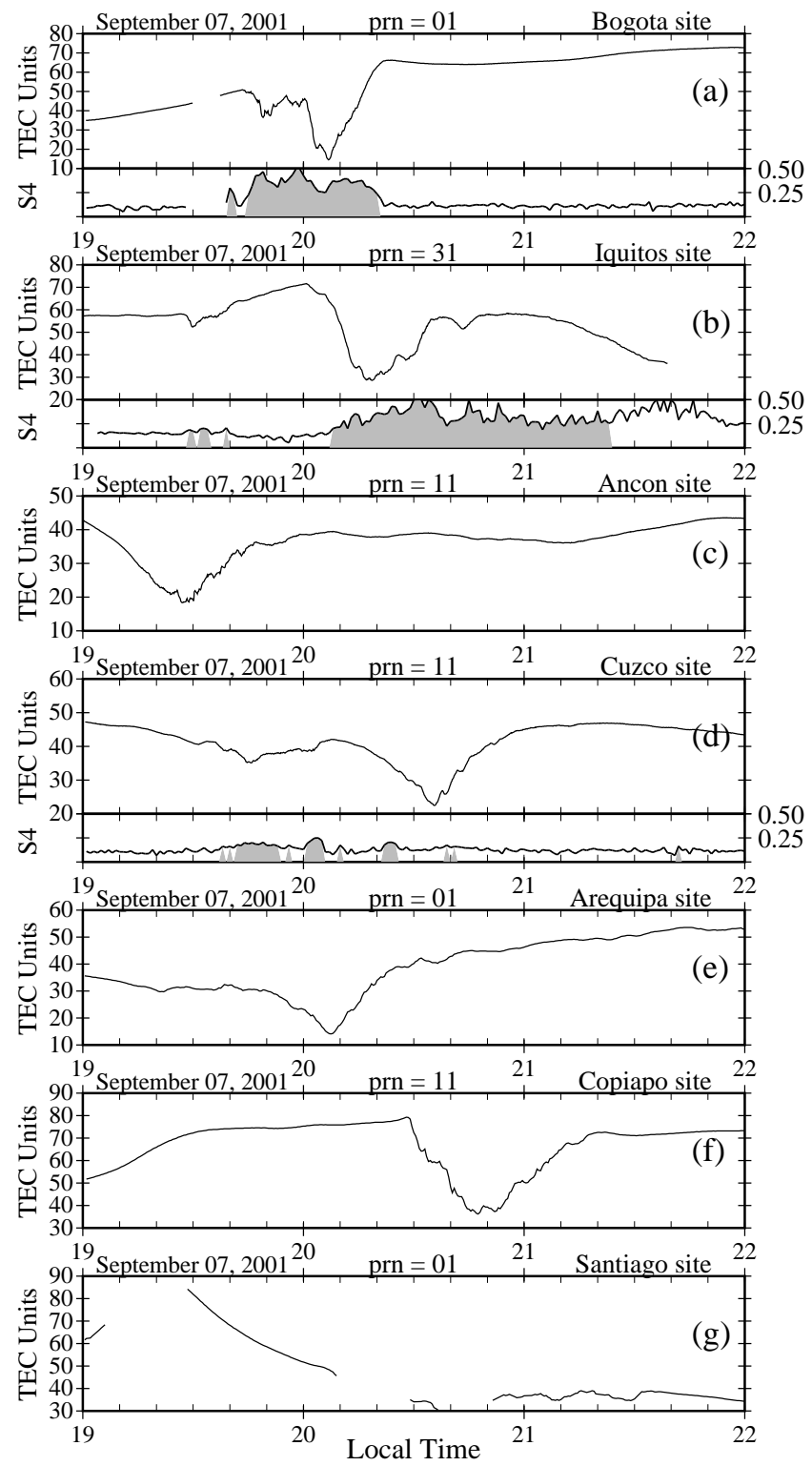

Fig. 2. Values of absolute TEC measured at several sites using signals from 3 GPS satellites. In all of these passes TEC depletions are evident, sometimes exceeding 50 TEC units $\left(10^{16} \mathrm{el} / \mathrm{m}^{2}\right)$. The additional sub-panel plotted below the Bogota, Iquitos and Cuzco TEC data corresponds to the S4 GPS scintillation index. Note that the minimum at Arequipa coincides with the minimum at Bogota, which is located $\sim 200 \mathrm{~km}$ to the west. As the bubbles move toward the east, TEC depletions should be observed at Bogota tens of min ahead of Arequipa. This discrepancy can be explained by the westward tilt of the plumes. See text for details.

the depletion. A TEC depletion originates when one or more plasma bubbles $\boldsymbol{E} \times \boldsymbol{B}$ drift across the satellite ray path. The general morphology of TEC depletions and their association with strong levels of VHF scintillations were described by DasGupta et al. (1983). More recently, Weber et al. (1996) have showed that there exists a strong correlation between TEC depletions and airglow $630.0 \mathrm{~nm}$ depletions, endors- ing the view that TEC depletions are a manifestation of the equatorial plasma depletions (also called bubbles). In this section, we use the information about TEC depletions gathered by a network of GPS receivers to infer the presence and the north-south extension of plasma bubbles. Nevertheless, we are aware that other non-bubble-related processes could produce quick reductions in the TEC value, and lead to a mistaken identification of the TEC depletions. Processes such as the nighttime decay of the F-layer and the density re-distribution caused by the fountain effect also lessen the TEC value. However, these two types of processes result in shallow TEC slopes and an absence of the recovery segment. We have excluded these cases from our statistics of TEC depletions. Different than previous studies, the TEC depletions presented here were sequentially detected by several of the 10 receivers located at different longitudes, providing a glimpse of the temporal evolution of the plasma depletions. Due to the relatively slow east-west motion of the GPS satellites, it is fair to say that the plasma depletions are traversing a quasi-stationary receiver-satellite link. We also note that the temporal duration of the passage of TEC depletion is a function of the bubble width and the satellite elevation. A pass near zenith will provide a TEC depletion width almost equal to the true bubble cross section. As the line-ofsight elevation becomes lower the TEC depletion will appear much wider. We also note that the depth of the TEC depletion is more likely to be a function of the local F-region peak density, the value of the underlying equatorial bottomside, and the magnetic latitude of the observation point. Assuming that the density remains constant along the depleted flux tube (Hanson and Bamgboye, 1984), there may exist a more pronounced depletion at the crest of the anomaly than at the magnetic equator.

Figure 2 shows TEC depletions measured at several sites, using signals from three different GPS satellites. On this day, TEC depletions were observed at all stations except Antuco. In addition, the receiver at Santiago suffered a loss of signals caused by the strong fading which was likely associated with TEC depletions. Figure 2a shows the passage of a TEC depletion, 35 TEC units $\left(10^{16} \mathrm{el} / \mathrm{m}^{2}\right)$ in depth, detected by the receiver at Bogota between 20:00 and 20:20 LT. Below the TEC curve, we display the S4 index that is calculated on-line using the signal received from each of GPS satellites. The gray shading indicates the times when the $\mathrm{S} 4$ index is above the noise level and the satellite elevation is above $20^{\circ}$. The TEC depletion of Fig. 2a is accompanied by high levels of GPS scintillations ( $\mathrm{S} 4=0.5$ ) on both the east and west walls of the depletion. Figure $2 b$ illustrates the same TEC depletion that was detected at Bogota 11 min earlier, but at Iquitos strong values $(0.5)$ of the $\mathrm{S} 4$ index were seen only on the west wall and weaker scintillations on the east side $(0.25)$ of the depletion. Due to the smaller look angle, the receiver at Iquitos observed the same TEC depletion that was seen at Bogota with an apparent wider width. The longitudinal separation between stations, and the time the TEC depletion takes to drift between them can be used to calculate the average zonal velocity of the plasma. We have used the transit time of TEC 
depletions between Ancon and Cuzco (65 min) that are separated by $550 \mathrm{~km}$ in the magnetic east-west direction, and calculated a $140 \mathrm{~m} / \mathrm{s}$ average zonal drift. Scintillations at Cuzco (Fig. 2d) were less intense, due to a smaller density that commonly prevails near the magnetic equator when the anomaly is fully developed. At Arequipa, the lowest value within the TEC depletion was observed at 20:08 UT. This is the same time that the minimum TEC was detected in Bogota (Fig. 2a), which is located $225 \mathrm{~km}$ west and several hundred kilometers north of Arequipa. This apparent discrepancy can be explained if we allow the bubbles to tilt westward at altitudes above the F-region peak (Woodman and LaHoz, 1976). The westward tilt will make the part of the TEC depletions that extends to higher latitudes to appear at slightly later times in a way similar to the plasma plumes seen with coherent radars. The Copiapo receiver (Fig. 2f) detected a 30 TEC units depletion spanning between 20:30 and 21:10 LT. As mentioned before, the receiver at Santiago was strongly affected by deep fades, likely associated with the turbulence within the depletions, suffered several data dropouts, and recorded only minor TEC disturbances.

Figure 3 displays the passage of two deep TEC depletions, which were observed by several of the receivers on 6 February 2002. Figures 3a-3i display TEC values collected from signals transmitted only by 2 GPS satellites. The subionospheric intersections between satellite 26 and the sites at Bogota, Iquitos, Pucallpa, Ancon and Cuzco varied in a south to north fashion, following a direction almost aligned with the local field line. The ionospheric penetration point from GPS satellite 09 passed south of Arequipa, Iquique, Copiapo, and Antuco, moving from west to east. Figure 3a shows that GPS scintillations at Bogota are equally intense on both sides of the depletion. However, at lower magnetic latitudes stations such as Iquitos and Cuzco (Figs. 3b and $3 e$ ), we observed that the west wall of the depletion possesses larger S4 values than the east side. Similar to Fig. 2 the plasma bubbles drift through the stations' fields-of-view at slightly different times. This means that a plasma bubble aligned with the B field and with no tilt in altitude will sequentially go through Ancon, Pucallpa, Bogota, Iquitos and Cuzco. If the bubble is tilted in altitude, as most of them are, then the station located further poleward, Bogota, may detect the TEC depletion after it has passed over a more equatorward station located further to the east, as Iquitos. This is the most likely physical scenario that can explain the TEC data recorded on 6 February 2002, as the first TEC depletion was seen at Iquitos at 20:25 LT, then at Bogota at 20:40 LT, and later at Cuzco $\sim 20: 45$ LT. In addition, traces of the temporal variability of the sub-ionospheric intersections from different stations but toward the same GPS satellite display almost parallel curves separated by the distance between the stations. It is quite significant that the Ancon and Pucallpa stations did not observe any TEC depletion before 20:25 LT. The implication of the last statement is that the depletion, seen at Iquitos at 20:25 LT, appeared in a location between Pucallpa and Iquitos, near the $74^{\circ} \mathrm{W}$ meridian and was triggered approximately at 20:20 LT. A different TEC depletion was seen
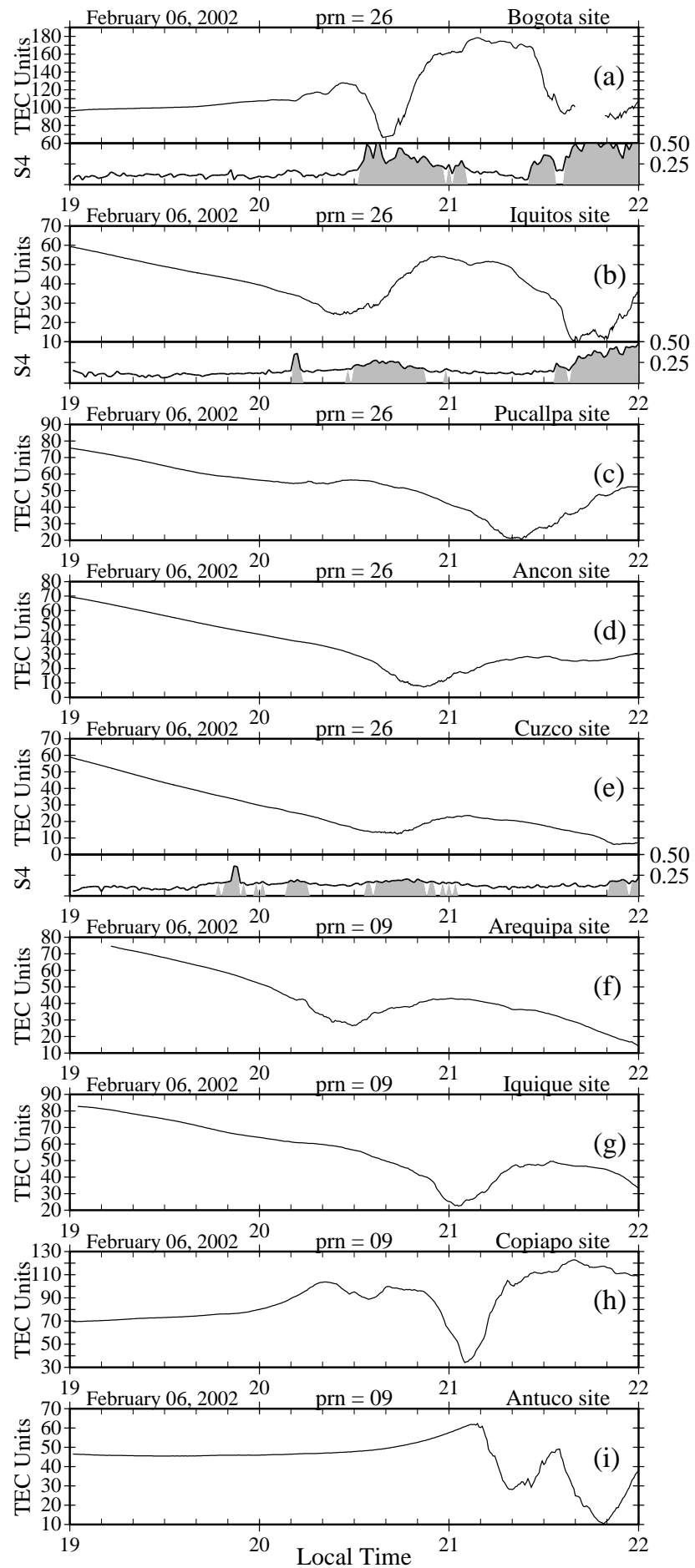

Fig. 3. Same as Fig. 2, but for 6 February 2002. Plasma bubbles drift through the stations fields-of-view at slightly different times. One TEC depletion was seen first at Iquitos at 20:25 LT, then at 20:40 LT at Bogota, and later at Cuzco 20:45 LT. Ancon and Pucallpa did not observe the TEC depletion, suggesting that the depletion developed in a location between Pucallpa and Iquitos, near the $74^{\circ} \mathrm{W}$ meridian and approximately at 20:20 LT. 

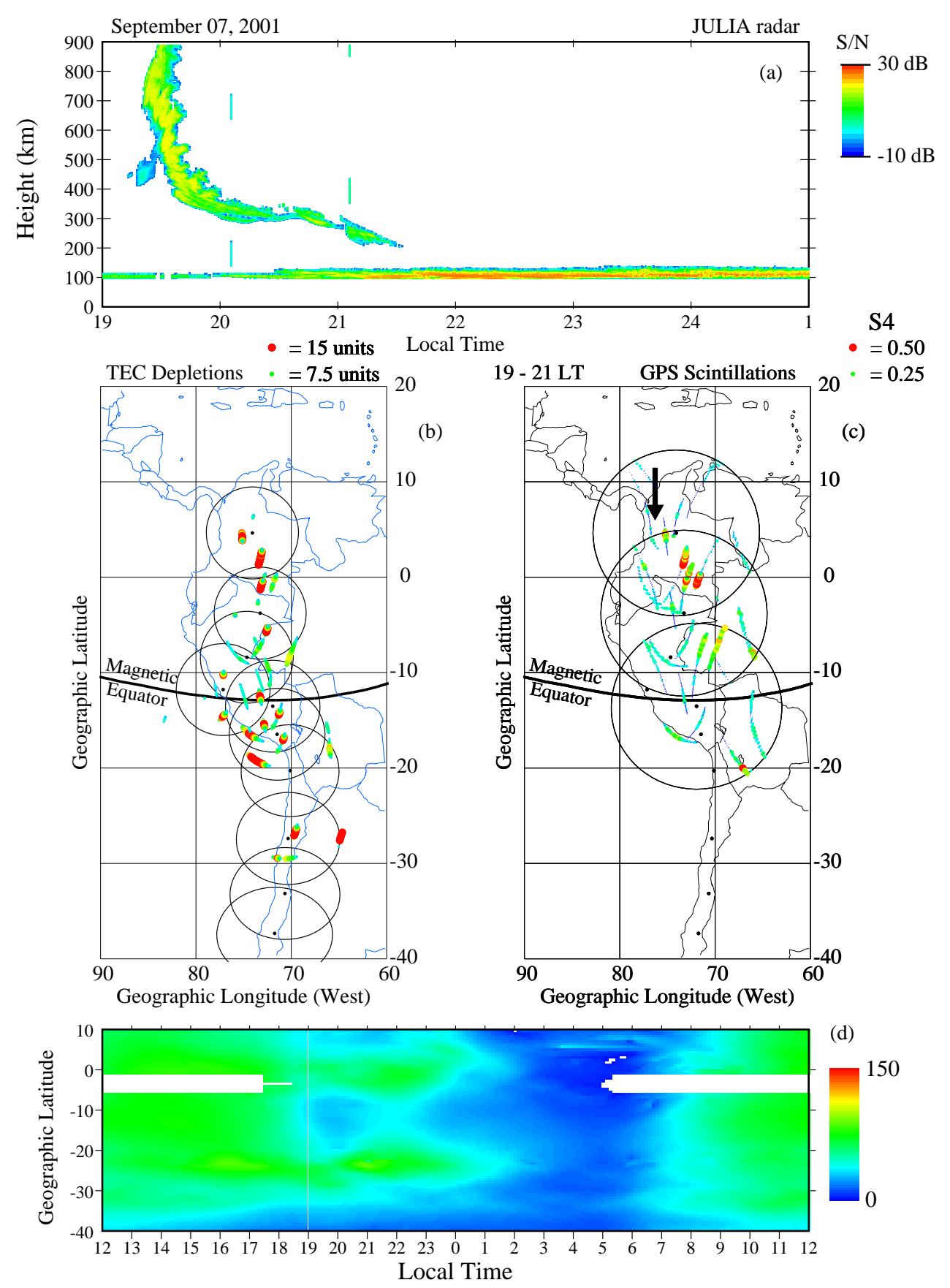

Fig. 4. The top panel shows range-time-intensity plot of a radar plume and a bottomside trace observed by the JULIA radar on 7 September 2001. The middle panels show maps of TEC depletions and GPS scintillations detected by the GPS receivers in South America. The lower panel displays absolute TEC latitudinal profiles measured between 12:00 LT on 7 September and 12:00 LT on 8 September 2001.

first in Ancon at 20:50 LT very close to the zenith direction. This depletion drifted through Pucallpa (21:20 LT), Bogota (21:38 LT), Iquitos (21:40 LT) and later Cuzco at 21:55 LT. The level of depletion in the northern crest (Bogota) was 60 TEC units. At Copiapo, near the southern crest of the anomaly the depletion was also 60 units, which indicates that the amount of depletion is approximately symmetric with respect to the magnetic equator. Nevertheless, as we will see in the following section, the TEC latitudinal profiles were not well symmetric. Note that the TEC value at Copiapo is above 100 TEC units, which for this local time is indicative that the southern crest of the anomaly was situated close to this site. The Antuco site, located $\sim 1000 \mathrm{~km}$ south of Copiapo, was likely located south of the southern crest. However, two deep depletions of 20 TEC units were seen here. This fact suggests that under some circumstances a TEC depletion can be located near the poleward limits of the anomaly and map to very high apex altitudes. 


\section{Case Studies}

In Sect. 3 we presented TEC depletions observed near the anomaly crests that were as large as 60 TEC units in depth, but close to the magnetic equator the TEC depletions were only 20 TEC units or less. In this section, we introduce three case studies to confirm the inherent association between TEC depletions, GPS scintillations and radar plumes.

\subsection{September 2001}

Figure 4a shows the JULIA power map measured on 7 September 2001, in which we observed a single plume, extending at least $900 \mathrm{~km}$ altitude at 19:30 LT. The correspondence of this radar plume and a TEC depletion containing low density plasma is demonstrated in Fig. $2 \mathrm{c}$ by the presence of a 15-unit TEC depletion passing near Ancon, also at 19:30 UT. No additional plumes were seen at Jicamarca during the rest of the evening, although a bottomside trace was detected with JULIA lowering in altitude between 19:40 and 21:30 LT. In association with the bottomside trace, no TEC depletions were observed near the Jicamarca longitude. Nevertheless, other TEC depletions developed far to the east of the $76^{\circ} \mathrm{W}$ meridian. Also significant was the absence of UHF scintillations (not shown here) after 20:00 LT at the Ancon F7 sub-ionospheric intersection (see Fig. 1). This lack of UHF scintillations and the absence of TEC depletions larger than 2 TEC units, implied that the JULIA bottomside trace of 7 September 2001 was not associated with significantly large TEC depletions, and if 1-km irregularities existed, they were constrained to the bottomside F-region and probably generated a very low level of UHF scintillations below the detection threshold of the Ancon system.

Figure $4 \mathrm{~b}$ displays the location and the magnitude of the TEC depletions that were identified in the TEC profiles for all stations and all satellites passes observed between 19:00 and 21:00 LT. This plot denotes three important features common to the three events presented in this section. First, the latitudinal extension of the TEC depletions is quite symmetric with respect to the magnetic equator. Secondly, the depth of the TEC depletion is less at the equator ( $<8$ units) and larger at the crests ( $>30$ units). Thirdly, the latitudinal extension of the depletions agrees quite well with the maximum latitude of scintillations.

Figure 4c shows the L1 GPS scintillations measured with the receivers deployed at Bogota, Iquitos and Cuzco between 19:00 and 21:00 LT. Scintillations from Pucallpa were not included due to the strong contamination of the S4 index produced by signal multi-paths. The magnitude of the S4 index has been color coded according to the scale indicated in the upper right corner. The $\mathrm{S} 4$ scintillation index is equal to 0.4 at the location of the northern crest where the density is the largest, but decreases to 0.2 at the trough. The scintillations associated with the radar plume are seen to reach $16^{\circ}$ magnetic latitude (see arrow in Fig. 4c). A field line crossing the F-region at this latitude maps to an apex height of $1000 \mathrm{~km}$. This maximum altitude inferred from the GPS scintillation does not contradict the smaller apex altitude of the plume since the JULIA range-time plot was limited to $900 \mathrm{~km}$.

Figure $4 \mathrm{~d}$ shows a color-coded representation of the TEC values measured on 7 September 2001, plotted as a function of latitude and local time. At 19:00 LT, the TEC value near the magnetic equator $\left(-12^{\circ}\right.$ geographic latitude) diminished rapidly and the amplitude of the crests increased slightly, indicating a re-energization of the fountain effect and the development of a more pronounced anomaly. The anomaly remained visible until 02:00 LT, when the TEC latitudinal profiles became more uniform and adopted a typical nighttime value of 15 units. On this day the anomaly was quite symmetric, centered at the magnetic equator, and with both crests possessing nearly the same width.

\subsection{December 2001}

Figure 5 shows the intensity of coherent echoes measured by JULIA on 3 December 2001, the locations of TEC depletions and GPS scintillations superimposed on a geographic layout, and $24 \mathrm{~h}$ of TEC latitudinal profiles centered on local midnight. The JULIA map indicates the existence of a $100-\mathrm{km}$ thick bottomside layer, which starts right after sunset and lasts until 23;30 LT. A single radar plume appeared at 20:35 LT and extended up to $720 \mathrm{~km}$ altitude. GPS scintillations corresponding to this day (Fig. 5c) show that the latitudinal extension of scintillations has a strong variability as a function of longitude. It reaches $15^{\circ}$ magnetic latitude (MLAT) at $73^{\circ} \mathrm{W}$ longitude, but only $13^{\circ}$ MLAT near the Jicamarca longitude (see arrow). A plume rising to $720 \mathrm{~km}$ maps to $12.7^{\circ}$ MLAT, which is in very good agreement with the maximum extension of GPS scintillations at the Jicamarca longitude. Figure 5b shows that on this day the TEC depletions have depths smaller than the depletions seen on 7 September 2001. The TEC depletions are 6 units near the equator and about 10 units at the anomaly, much smaller than 12 and $>40$ units that was seen at the equator and the crests on 7 September 2001. Notwithstanding, the GPS scintillations of 3 December 2001 are more intense, containing S4 values near 0.6 at the northern crest and 0.4 near the trough. Another important difference is the low level of UHF scintillations that was detected on 7 September $2001(\mathrm{~S} 4=0.3)$ and the more intense $(\mathrm{S} 4=0.7)$ and long lasting event of 3 December 2001. On the latter day, a decreasing level of scintillations was seen between 20:00 LT and the early morning hours (06:00 LT).

Figure $5 \mathrm{~d}$ shows the formation of the TEC anomaly that occurred right after sunset. Both the northern and southern crests are easily distinguishable after 19:30 LT. However, both crests are not symmetric, presenting different peak values, widths and lifetimes. It has been indicated that a northward directed meridional wind is able to reduce the amplitude of the southern crest and amplify the northern crest by transporting the plasma along field lines. The TEC distribution of 3 December 2001 can be well explained by this wind mechanism. Maruyama and Matuura (1984) have suggested that a meridional wind with this characteristic might 

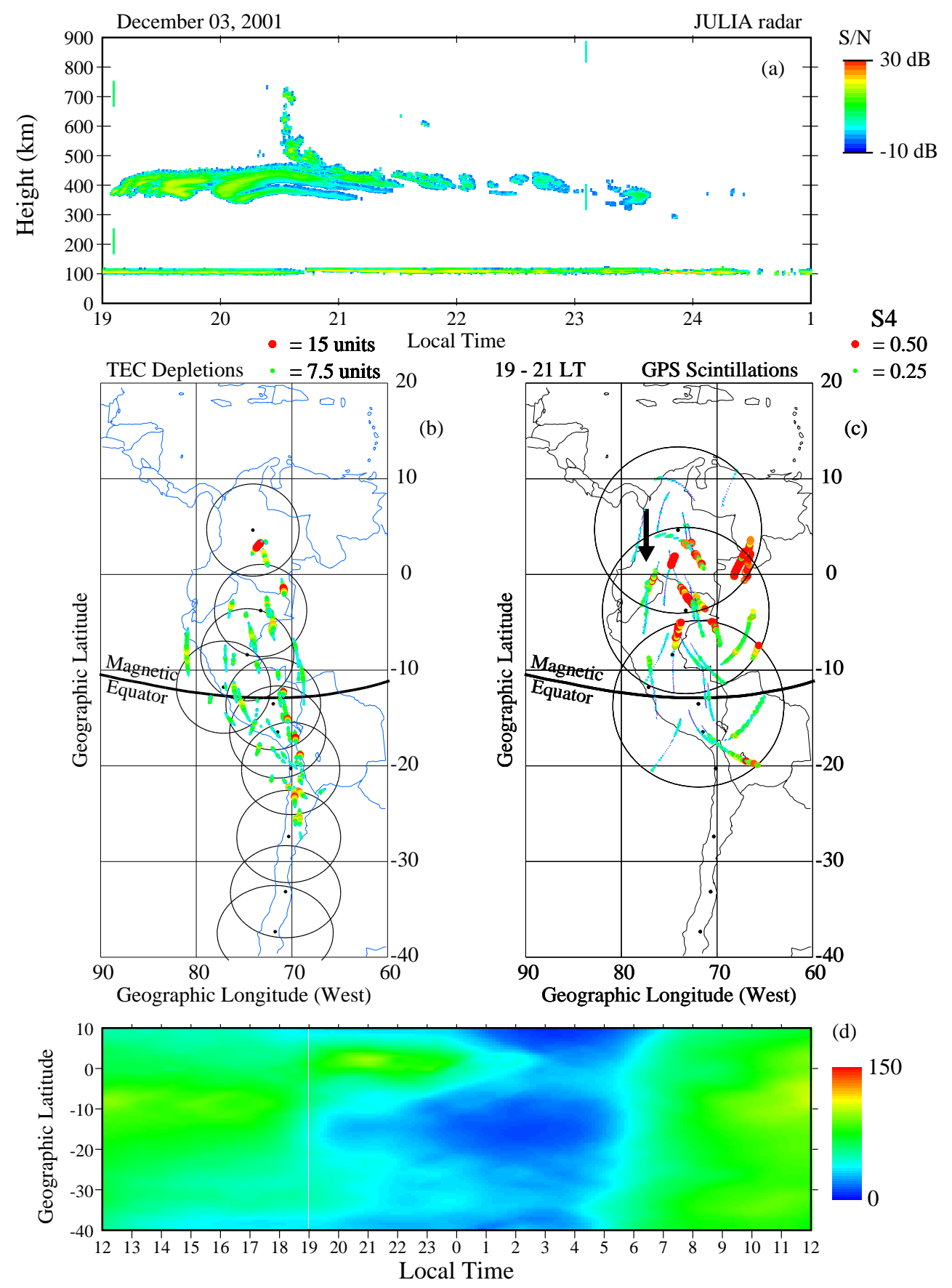

Fig. 5. Same as Fig. 4, but corresponding to 3 December 2001. The top panel shows a single radar plume developing at 20:40 LT, and reaching $700 \mathrm{~km}$. The TEC depletion and the GPS scintillations, at locations near Jicamarca, extend up to $13^{\circ}$ magnetic latitude. The TEC profiles seen near sunset are highly asymmetric. Nevertheless, strong scintillations were detected this day.

inhibit the growth of the equatorial plasma bubbles. However, we did not observe an inhibition of the irregularities on 3 December 2001 and on many other nights, which are presented below in Sect. 5. It has been recently suggested by Devasia et al. (2002) that the transequatorial wind may act as an instability suppressor but only when the F-region altitude is below a certain limit. This hypothesis could explain the maintenance of ESF during nights when the anomaly is widely asymmetric. In Sect. 7, we put forth another hypothesis that might explain the variability of the TEC profiles that commonly exist during GPS scintillations events.

\subsection{February 2002}

Figure 6 shows a plot of JULIA coherent echoes, TEC depletions, GPS scintillations, and TEC latitudinal profiles recorded on 3 February 2002. The JULIA map illustrates the 

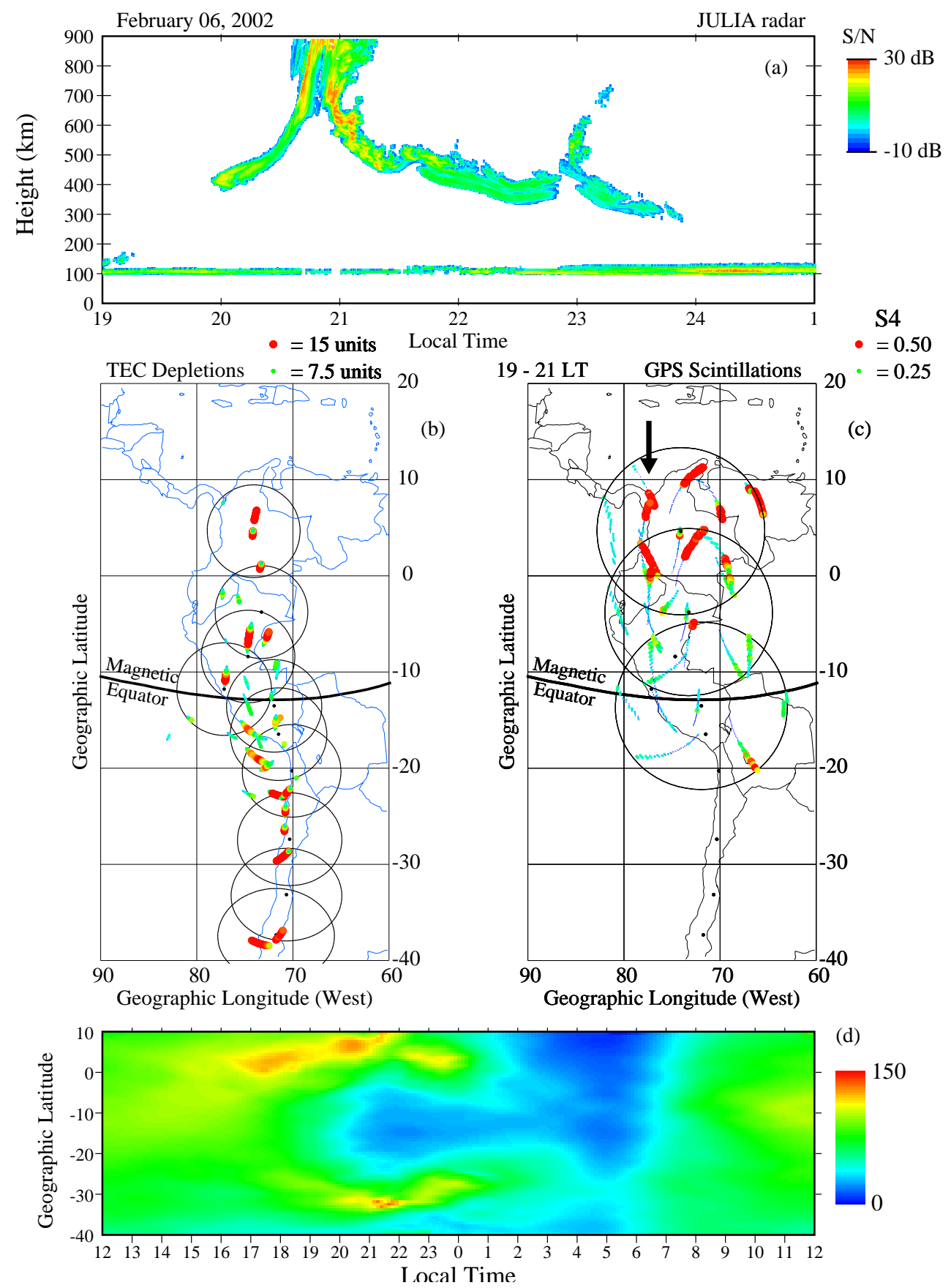

Fig. 6. Same as Fig. 4, but corresponding to 6 February 2002. The radar map shows two plumes. The first occurs between $20: 40$ and 21:10 LT and extends beyond $900 \mathrm{~km}$. The TEC depletions and GPS scintillations detected at several sites extend up to 23 degrees magnetic latitude and indicate that the plasma bubbles extend up to $1400 \mathrm{~km}$ altitude.

extension of two radar plumes that developed from a bottomside trace that was seen to continuously decrease in altitude. The first plume was seen at 21:00 LT, when the F-region bottomside had raised up to $600 \mathrm{~km}$ altitude. The strength of the echoes suggested that this plume extended well beyond the $900 \mathrm{~km}$ altitude limit of Fig. 6a. The second plume was detected at 23:00 LT and reached $700 \mathrm{~km}$ altitude. Figure $6 \mathrm{~b}$ displays the geographic location of several TEC depletions measured by all ten GPS receivers. Similar to the other two case-events, the magnitude of the depletions increased at latitudes further away from the equator, but in this event the depletions were seen up to $20^{\circ} \mathrm{N}$ MLAT ( $8^{\circ}$ geographic lat) and $25^{\circ} \mathrm{S}$ MLAT ( $38^{\circ} \mathrm{S}$ geographic lat). The depletions detected at the Ancon and Cuzco sites were 20 units, but reached 40-50 units near the crests of the anomaly. As expected the magnitude of the GPS scintillation index (Fig. 6c) is much larger during this day. S4 values as high as 0.8 were encountered at $23^{\circ}$ MLAT, but only 0.3 near the magnetic 

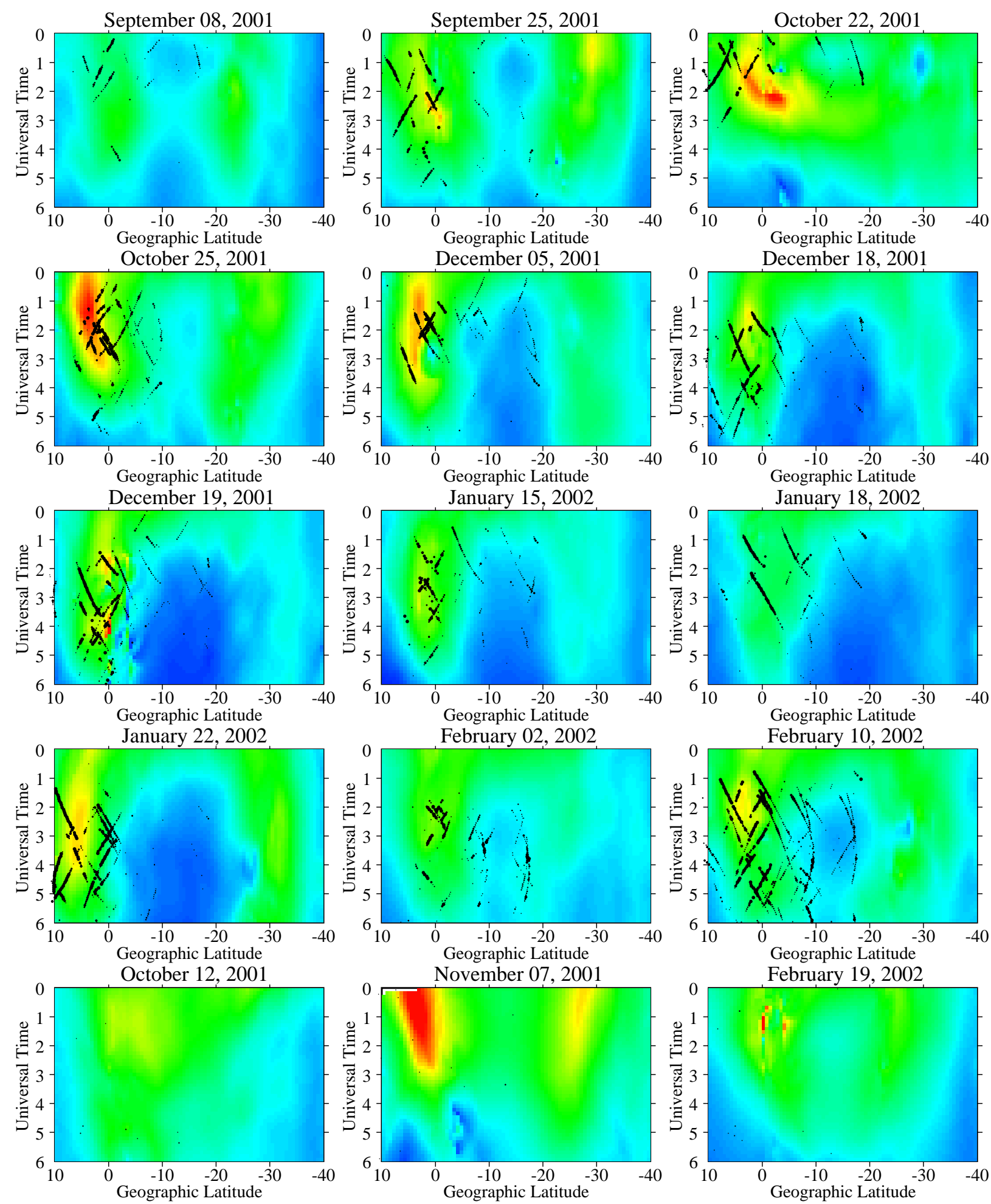

Fig. 7. Absolute TEC distributions for 15 case study events observed during the equinox and December solstice seasons. The first 12 cases correspond to days of GPS scintillations and the last 3 (the lower row) are for days with no scintillations. The black traces indicate the location, time and intensity of the GPS scintillations. 
equator. UHF scintillations, measured at Ancon with the $250 \mathrm{MHz}$ system, were also much stronger than the previous two cases. The UHF scintillations detected at both F7 and F8 sub-ionospheric penetration points contained several bursts of saturated values. The TEC profiles of Fig. $6 \mathrm{~d}$ indicates that the TEC anomaly becomes more pronounced and separated from the magnetic equator at 17:00 LT. Both crests are displaced at least $19^{\circ}$ MLAT away from the magnetic equator at 22:00 LT. This event displays one of the largest anomaly displacements that we have seen. The location of the crests $19^{\circ}$ away from the magnetic equator correlates quite well with the largest latitudinal extensions of scintillations. Right after 22:00 LT, both crests retracted and moved closer to the magnetic equator until 01:00 LT when they faded. We interpret that this separation of the crests of the anomaly is the result of a strong fountain effect, driven by a large vertical drift that was most likely directed upwards until 22:00 LT when it reversed to a downward direction.

\section{Simultaneous observations of TEC and GPS scintilla- tions}

Figure 7 shows the temporal evolution of the TEC profiles for 15 days selected between the months of September 2001 and February 2002. The TEC values presented in this figure correspond to the first $6 \mathrm{~h}$ of the evening, starting after local sunset (00:00 UT). The dark traces superimposed on the color-coded TEC data illustrate the scintillation S4 index measured at Bogota, Iquitos and Cuzco. They are placed at the latitude of the sub-ionospheric penetration point and at the times when the S4 index exceeded the noise level (0.20). The purpose of this figure is: 1) to demonstrate the close relationship between the location of scintillations and the latitudinal extension of the equatorial anomaly, and 2) to indicate the rapid response of GPS scintillations to the evolution of the TEC profiles. The 12 frames in the four upper rows show data for days with scintillation activity. The three frames in the bottom row are for nights with no scintillation activity. It is worthwhile to note that between 00:00 and 06:00 UT the nighttime F-region normally decays in a slow manner. In addition, during the early evening hours there commonly exists a rapid plasma re-distribution along the field lines: the fountain effect. An upward drift near the equator drives the direct fountain effect (Hanson and Moffett, 1966) by moving the plasma poleward, reinforces the amplitude of the crests, and reduces the density at the trough. A downward vertical velocity creates a reverse fountain effect (Sridharan et al., 1993; Balan and Bailey, 1995), moves both crests equatorward, diminishes the size of the crests, and increases the TEC value at the trough.

The frame labeled 8 September 2001 (7 Sept 2001 in local time), placed in the upper left corner, reproduces the TEC latitudinal profiles of Fig. 4d, but here we introduce the scintillation information within the context of the TEC variability. GPS scintillations appeared at 00:00 UT, when the TEC crest was fairly constant; the trough TEC value was small and the crest/trough ratio close to 2 . Scintillations ceased between 02:20 and 04:00 UT during a period when the TEC value at the trough increased from 35 to 45 units. This evolution of the TEC profiles follows the typical variability of the TEC latitudinal profiles when a reverse fountain develops. Scintillation activity resumed after 04:00 UT when the trough decreased and the TEC crest increased in amplitude, suggesting a late re-initiation of the fountain effect. The frame for 25 September 2001 presents a case when both crests of the anomaly were relatively wide and large. Scintillations persisted for almost two hours after both crests decreased due to the effect of a reverse fountain. Notice that for both days described above, and for most of the cases in Fig. 7, we detected high levels of GPS scintillations confined within the boundaries of the anomaly. A more dramatic case of the control that the variability of the anomaly exerts on the existence of GPS scintillations is shown in the frame corresponding to 22 October 2001, a day of intense magnetic activity. The rapid equatorward motion of the crest, seen at 02:00 UT, is again the manifestation of a large downward vertical drift that drives the reverse fountain. Similar to the frame for 8 September 2001, this example shows an excellent correlation between the equatorward displacement of the anomaly and the suppression of scintillations. The sub-frames in the second and third rows show events in which the amplitude of the anomaly was asymmetric. These events were seen during the December solstice when it is typical to have a meridional wind blowing northward during the afternoon and early evening hours (Meriwether et al., 1986). Notice that in two cases (19 December 2001 and 18 January 2002), the southern crest was almost non-existent. Nevertheless, high levels of GPS scintillations were detected on the northern part of the anomaly. We do not have records of GPS scintillations at regions south of the magnetic equator. However, we do indicate that the UHF system at Antofagasta $\left(22^{\circ} \mathrm{S}\right.$ latitude, $10^{\circ} \mathrm{S}$ magnetic latitude) recorded strong, followed by moderate levels of scintillations between 00:20 and 08:00 UT. These two cases also emphasize the notion that the regions of scintillations are limited poleward within regions where the anomaly is fully developed and prominent in comparison to the TEC trough. The 25 October 2001 event shows the northern crest moving inward toward the equator and the amplitude of the crest decaying very rapidly after 02:00 UT. GPS scintillations were observed to stay for 3 more hours after the start of the reverse fountain. During the event of 5 December 2001, scintillations decayed much rapidly after the crest amplitude diminished from 140 to 100 units at 03:50 UT. The following 2 frames, corresponding to 18 and 19 December 2001, display the northern crest slowly decaying with no apparent increase or decrease of the TEC value at the trough. During these two days of no apparent fountain effects between 00:00 and 06:00 UT, GPS scintillation persisted even after 06:00 UT. This is longer than the other cases when the reverse fountain was active. On these two days GPS scintillations lasted until the amplitude of the crest was below 40 TEC units. The 15 January 2002 TEC panel presents a case of moderate levels of GPS scintillations over 

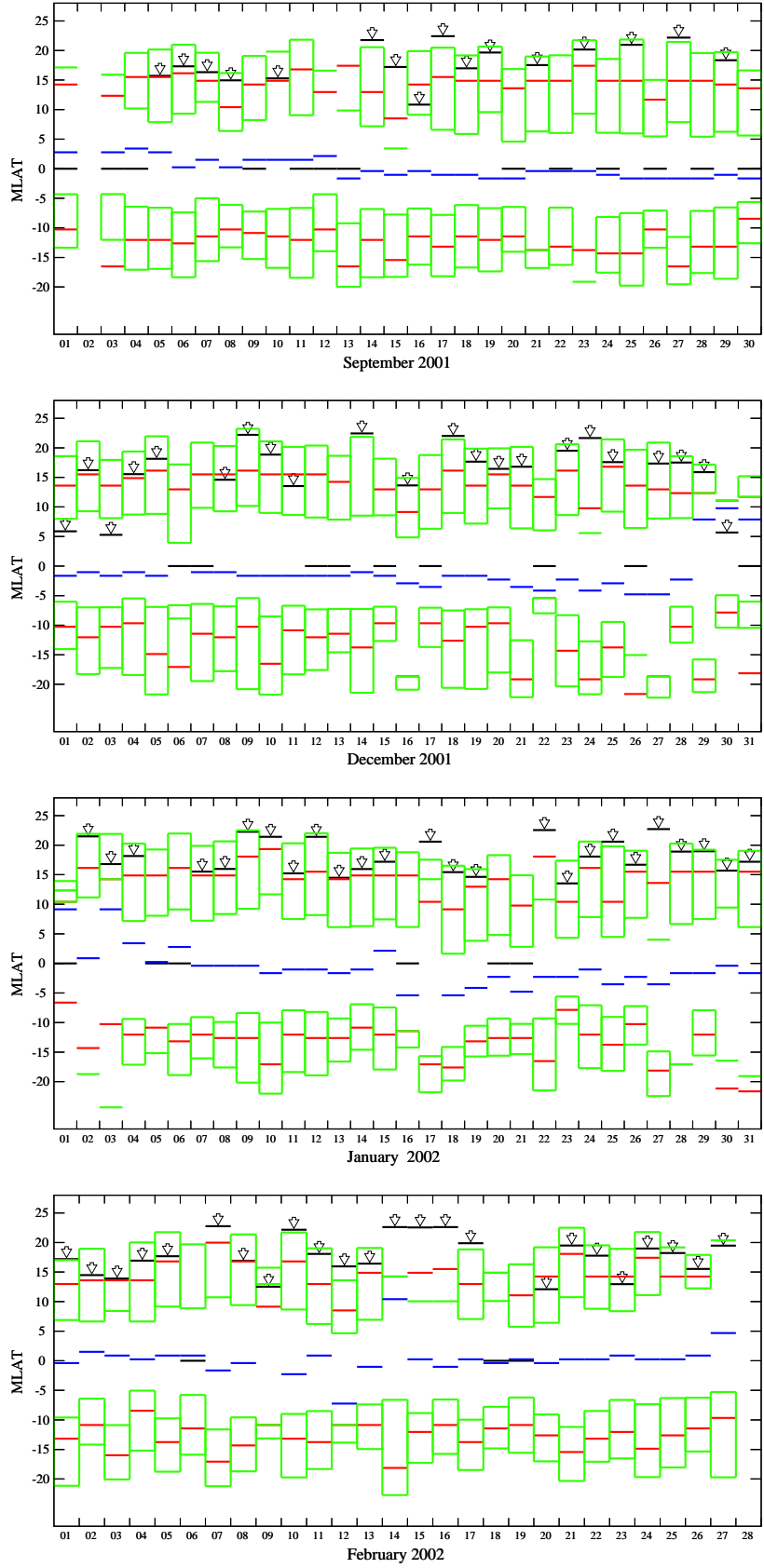

Fig. 8. Latitudinal distribution of the location of the anomaly for the months of September, December, January and February. The blue trace near $0^{\circ}$ magnetic latitude indicates the location of the trough. The red lines are used to point out the locations of the anomaly crests. The green lines indicate the extension where the crests diminish 50\%. The short black lines and the arrows seen near the northern boundary of the northern crest indicate the maximum latitude of GPS scintillations. Note that only in a few cases does the maximum latitude of scintillations extend beyond the limits of the anomaly.

the anomaly peak and weak scintillations within the trough region. The frame for 22 January 2002 shows the northern crest of the anomaly displaced up to $19^{\circ}$ magnetic latitude and GPS scintillations extending beyond our latitudinal cov- erage. The frame for 2 February 2002 shows the crests of the anomaly placed near $13^{\circ}$ magnetic latitude and the GPS scintillations confined to a maximum latitudinal extension of $14^{\circ}$ magnetic latitude. On this day scintillations ceased at 05:30 UT during a period when the reverse fountain was in effect. The frame corresponding to 10 February 2002 shows a pattern of strong scintillations that initiated at 01:00 UT. At this time, there is a re-initiation of the fountain effect, shown as a decrease of the TEC trough and an increase of the northern crest. Nevertheless, GPS scintillations persisted for several hours after the anomaly had started retracting equatorward. On this day, GPS scintillations were observed to extend beyond the limit of northern boundary of the northern crest $\left(22^{\circ}\right.$ MLAT). However, the southern crest reached a larger magnetic latitude equal to $27^{\circ}$.

All three cases displayed in the bottom row were not associated with GPS and UHF scintillations at all the stations. The salient feature seen in all three panels is the relatively high level of TEC values at the magnetic equator $\left(\sim 12^{\circ} \mathrm{S}\right)$. The plot for 12 October 2001 shows a fairly uniform TEC latitudinal distribution. In this plot a modest TEC increase occurs between $0^{\circ}$ and $6^{\circ} \mathrm{S}$ at 01:00 UT. The profiles for 7 November 2001 show two well-defined crests and a prominent northern peak, but the trough is quite broad with a TEC value above 70 TEC units. The event of 19 February 2002 shows a quasi-uniform TEC distribution with a narrow and short-lived crest. The cases presented in Fig. 7 summarize the great variability of the TEC profiles during 15 nights when all 10 GPS receivers were operating concurrently.

\section{Statistics}

Figure 8 presents the day-to-day variability of the extension of the equatorial anomaly measured at 20:00 LT. This time commonly corresponds to the initiation of ESF/scintillations. Figure 8 displays the magnetic latitude of the location of both crests of the anomaly (red traces), the trough (blue trace), and the 50\% amplitude decay of the crests (green boxes). We also indicate the northern edge of the region subject to GPS scintillations using a bold line and an arrow. The scintillation information originates from real-time calculations of the $\mathrm{S} 4$ index based on the 10-Hz amplitude of the L1 GPS signal recorded at three of the stations (Bogota, Iquitos and $\mathrm{Cuzco}$ ). Their combined scintillation-observing range stretches between $21^{\circ} \mathrm{S}$ and $12^{\circ} \mathrm{N}$ geographic latitude. Days without GPS scintillation activity are indicated by using a dark line placed at the magnetic equator. This study is restricted to display only the scintillation northern boundary, as we did not have access to scintillation information from GPS receivers located further south of the magnetic equator. The frames of Fig. 8 correspond, from top to bottom, to the months of September 2001, December 2001, January 2002, and February 2002. During days when insufficient TEC data prevented us from completely defining the boundary of the anomaly we left the green boxes incomplete, as can be seen at the northern poleward boundary on 1 and 3 September. The trough 

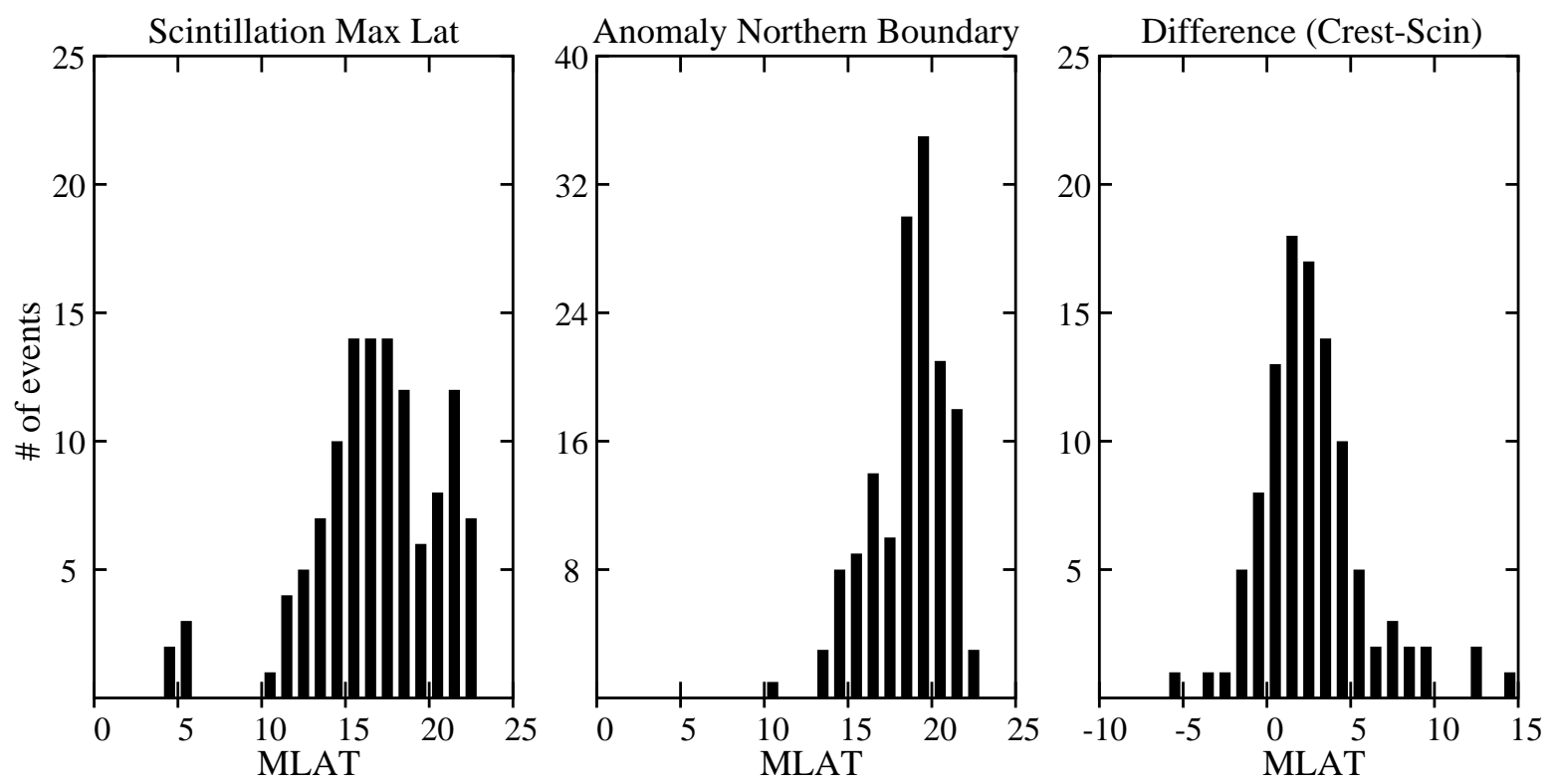

Fig. 9. The left histogram shows the maximum latitude of scintillations. The center panel displays the location of the northern boundary of the anomaly, defined as the poleward edge where the northern crest decreases $50 \%$ of its peak value. The right panel exhibits the distribution of the difference between poleward boundary of the anomaly and the maximum latitude of scintillations. Only in 9 cases out of 100 were GPS scintillations (and TEC depletions) seen poleward of the northern boundary of the anomaly.

was observed, most of the days, close to the magnetic equator. Exceptions are seen in early September, late December, 16-20 January and 12 and 27 February when the trough was displaced up to $7^{\circ}$ from the magnetic equator. The location and width of the crests also show a large degree of variability. In some cases, both crests of the anomaly are close to $10^{\circ}$ magnetic latitude, as seen on 8 and 26 September, 17 December, 23 January, and 12 February. But, on other occasions, they are nearly at $20^{\circ}$, as seen on 10 and 22 January and 7 February. The width of the crests were calculated by taking the difference between the crest and the trough TEC values, and recording the latitude where this difference falls off by $50 \%$. It is evident that for most of the days the northern and southern crests are not placed symmetrically with respect to the magnetic equator and do not have the same latitudinal span. The maximum latitude of scintillations also shows a great variability; sometimes it is only $5^{\circ}$ from the magnetic equator. But in other cases scintillations reach $23^{\circ}$ magnetic latitude; this latitude corresponds to the poleward limit of the combined field-of-view of the GPS network. There is no doubt that, for some of these events, scintillations and the anomaly continue extending further poleward, but these regions were beyond the observing boundaries of the existing chain of GPS receivers. During the 6-month period presented in this paper, we found that on 40 nights $(22 \%$ of all days) scintillations extended up to a latitude equal or greater than $20^{\circ}$ away from the magnetic equator. We also observed that while the amplitude of the crests show a prominent seasonal variability, the latitudinal location and extension of the anomaly display no significant seasonal dependence. We have also detected that for all months involved in this study, the northern crest was displaced toward more poleward latitudes than the southern peak of the anomaly.

Figure 9 illustrates the statistical distribution of the latitudinal extension of scintillations, the latitude of the anomaly northern boundary and a cross-comparison between them. The histogram on the left side reveals that for the majority of days, scintillations are confined to a magnetic latitude range that varies between $10^{\circ}$ and $23^{\circ}$. Nevertheless, there exist a small number of days when scintillations appeared only at latitudes very close to the magnetic equator, and the disturbed region extended no more than $4^{\circ}$ or $5^{\circ}$ to both sides of the magnetic equator. The center panel displays the statistical distribution of the location of the northern boundary (50\% decay) of the northern crest. This figure suggests that during the period that was analyzed in this study, the northern boundary of the anomaly varied between $14^{\circ}$ and $22^{\circ}$ magnetic latitude. The histogram on the right side shows the distribution of the difference between the northern boundary of the crests and the maximum latitude of GPS scintillations. Positive values correspond to cases when the anomaly boundary was located poleward of the region affected by scintillations. Then, we conclude that for most of the days scintillations are confined equatorward of the $50 \%$ fall off of the anomaly. This result suggests the existence of a relationship between the latitudinal extension of GPS scintillations (plasma bubbles) and the location of the crest of the anomaly. It is important to mention that on a few days, 8 days to be precise ( $\sim 9 \%)$, we observed GPS scintillations located more than $1^{\circ}$ poleward of the northern boundary ( $50 \%$ fall off) of the anomaly. 

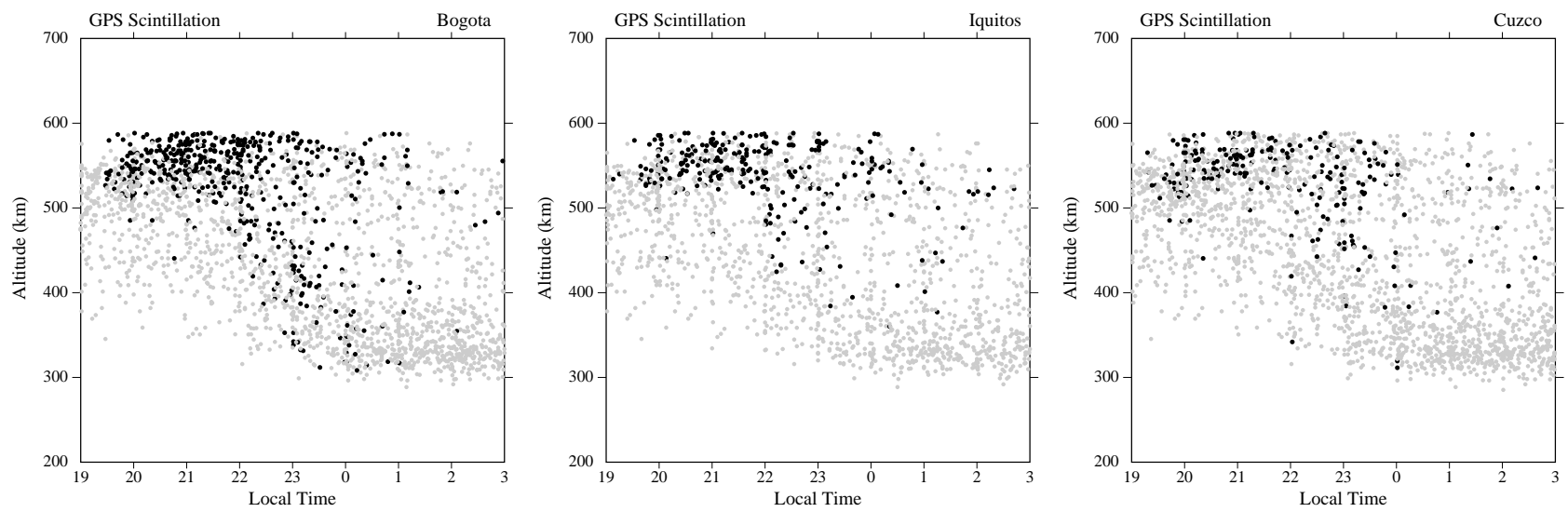

Fig. 10. $h m \mathrm{~F} 2$ value of the equatorial ionosphere during the ten-month observational period presented in this study. The gray dots correspond to events when the GPS scintillation index was below 0.20. The black dots are for S4 levels above 0.20.

Figure 10 displays a mass plot of the altitude of the Fregion peak measured by the Jicamarca digisonde between the months of September 2001 and June 2002. The peak altitude $(h m \mathrm{~F} 2)$ is plotted as a function of local time starting near local sunset. The $h m \mathrm{~F} 2$ values are calculated with the Artist software that runs simultaneously with the data acquisition process. Different gray shading is used to distinguish between the absence (light gray) and presence (black) of GPS scintillation. Each panel of Fig. 10 shows the $h \mathrm{mF} 2$ values binned as a function of the scintillation activity measured by the receivers placed at Bogota, Iquitos and Cuzco. Similar to results published by other researchers, we found a well-defined dependence of the appearance of GPS scintillations and the altitude of the F-layer. Between 19:00 and 21:30 LT, scintillations mostly appear when the layer is located above $500 \mathrm{~km}$ altitude. Nevertheless, a small number of events occur when $h m \mathrm{~F} 2$ is less than $500 \mathrm{~km}$ altitude. At local times later than 21:30 LT, the relative number of scintillation events with $h m \mathrm{~F} 2$ below $500 \mathrm{~km}$ drastically increases, as it is common to observe scintillations at altitudes varying between 300 and $500 \mathrm{~km}$. These events probably correspond to cases that outlived the descent of the F-region, and scintillations persisted during the nighttime decay. This feature is common to all three stations and usually starts near 21:30 LT. During the descent of the F-region, we found that the number of scintillation events detected at Cuzco, near the magnetic equator, was smaller than the number of events at other stations. This result is probably due to the much smaller density at the trough that makes the $\mathrm{S} 4$ level significantly close to the noise level. Figure 11 displays the altitude of the F-layer for all instances when TEC depletions were detected at the Bogota, Iquitos, Pucallpa, and Iquique stations. The red dots indicate cases when the depth of the depletions were larger than 30 TEC units. The blue dots are for depletions less than 30 units. The distribution of $h m \mathrm{~F} 2$ is quite similar to the distributions of Fig. 10 for GPS scintillations. Figures 10 and 11 demonstrate that equatorial plasma bubbles can survive up to 2 hours after the nighttime F-layer starts descending. We also indicate that plasma bubbles and GPS scintillations rapidly decay when the equatorial F-layer reaches $300 \mathrm{~km}$ altitude. For days when the $h m \mathrm{~F} 2$ remains at altitudes above $500 \mathrm{~km}$, scintillations and TEC depletions seem to last for longer periods and can be seen as late as 03:00 LT. The occurrence of GPS scintillations and TEC depletions when the F-region peak was below $500 \mathrm{~km}$ altitude warrants further study of the background conditions of the ionosphere during these cases.

A very informative statistics of the preferred ionospheric conditions that prevailed during the occurrence of scintillation/depletion events is presented in Fig. 12. This figure shows the $h m \mathrm{~F} 2$ measured at Jicamarca as a function of two key representative parameters of the TEC profiles: the crest-to-trough TEC ratio and the latitudinal separation of the northern crest. The left panel shows the $h m \mathrm{~F} 2$ versus the crest-to-trough ratio binned according to the presence (red and blue dots) and absence of scintillation (gray dots). The right panel displays the peak altitude as a function of the crest separation in degrees. Figures $12 \mathrm{a}$ and $12 \mathrm{~b}$ were constructed by estimating the maximum level of scintillations every hour the Bogota and Iquitos GPS receivers operated between sunset ( 19:00 LT) and 23:00 LT. Each scintillation value was paired with the corresponding F-region peak altitude measured at Jicamarca and the TEC latitudinal profile recorded with the GPS network. The red dots illustrate scintillation events observed before 22:00 LT, and the blue dots represent scintillation cases occurring before 23:00 LT. Figure 12 reveals that when the equatorial F-region peak is above $500 \mathrm{~km}$, GPS scintillations are able to develop for TEC ratios as small as 1.25 or as large as 6.0 , and crest separations between $6^{\circ}$ and more than $20^{\circ}$. But as the peak altitude becomes less than $500 \mathrm{~km}$ the TEC ratio becoms restricted to values larger than a threshold number and to crest separations exceeding a minimum value. Figure 12 implies that the TEC ratio threshold and the crest minimum separation increase as the altitude of the F-region peak becomes smaller. For an F-region peak near $400 \mathrm{~km}$ the TEC ratio needs to be higher than 2.5 and the crest separation larger than $12^{\circ}$. We also divided all the scintillation events in nine altitude sectors and looked for the minimum ratio and crest separation in each altitude block. 

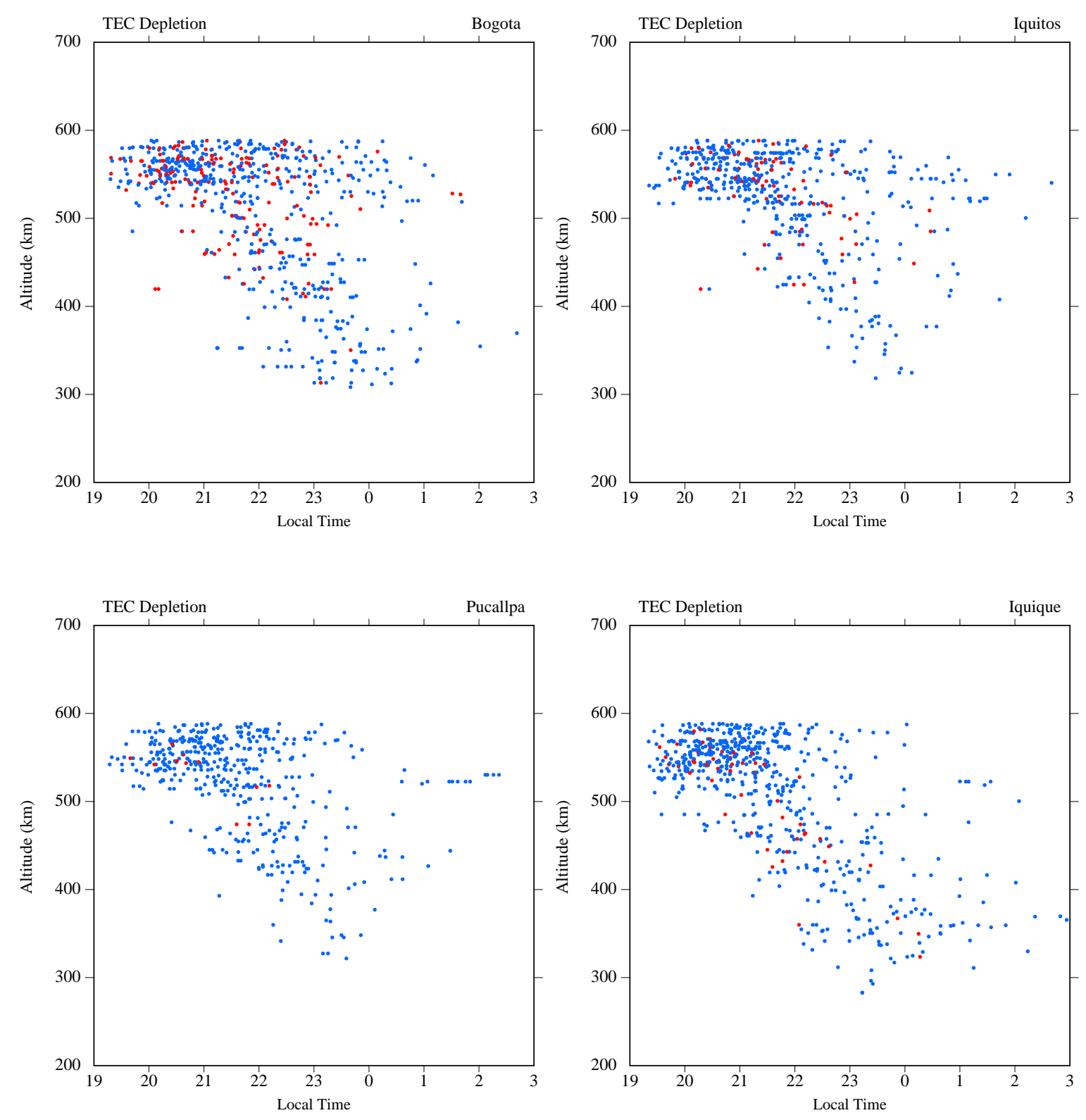

Fig. 11. $h m \mathrm{~F} 2$ values measured during the occurrence of TEC depletions measured with the network of GPS receivers. TEC depletions larger than 30 TEC units are depicted as red dots; values smaller than 30 units are indicated by blue dots. Mass plots for only 4 stations are presented here.

The inclined line in each panel depicts the best fit to these minimum points. These traces also indicate the almost linear relationship between the minimum crest separation (and crest/trough ratio) and the altitude of the F-region for all the scintillations events that were observed at Bogota and Iquitos. It is important to mention that most of the gray dots (times of no scintillations) are observed bunched at TEC ratios less than 2.2. Based on this data, it is possible to conclude that an equatorial F-region peak below $500 \mathrm{~km}$ does not necessarily imply an inhibition of the onset or persistence of GPS scintillation, but it does require the crest/trough TEC ratio to be 2 or higher and the crest separation to exceed $8^{\circ}$. The lower the F-region peak, the higher that the TEC ratio and the crest separation have to be for the flux tube to remain unstable to the initiation or persistence of GPS scintillations.

\section{Discussion}

TEC depletions provide precisely the total amount of plasma that is evacuated within a plasma bubble. In addition to this quantity, we have shown that other geophysical parameters can also be estimated if careful account of multiple sights of a plasma bubble are considered. These calculations are facilitated by the time progression of the ionospheric penetration points that look like nearly parallel curves when the 

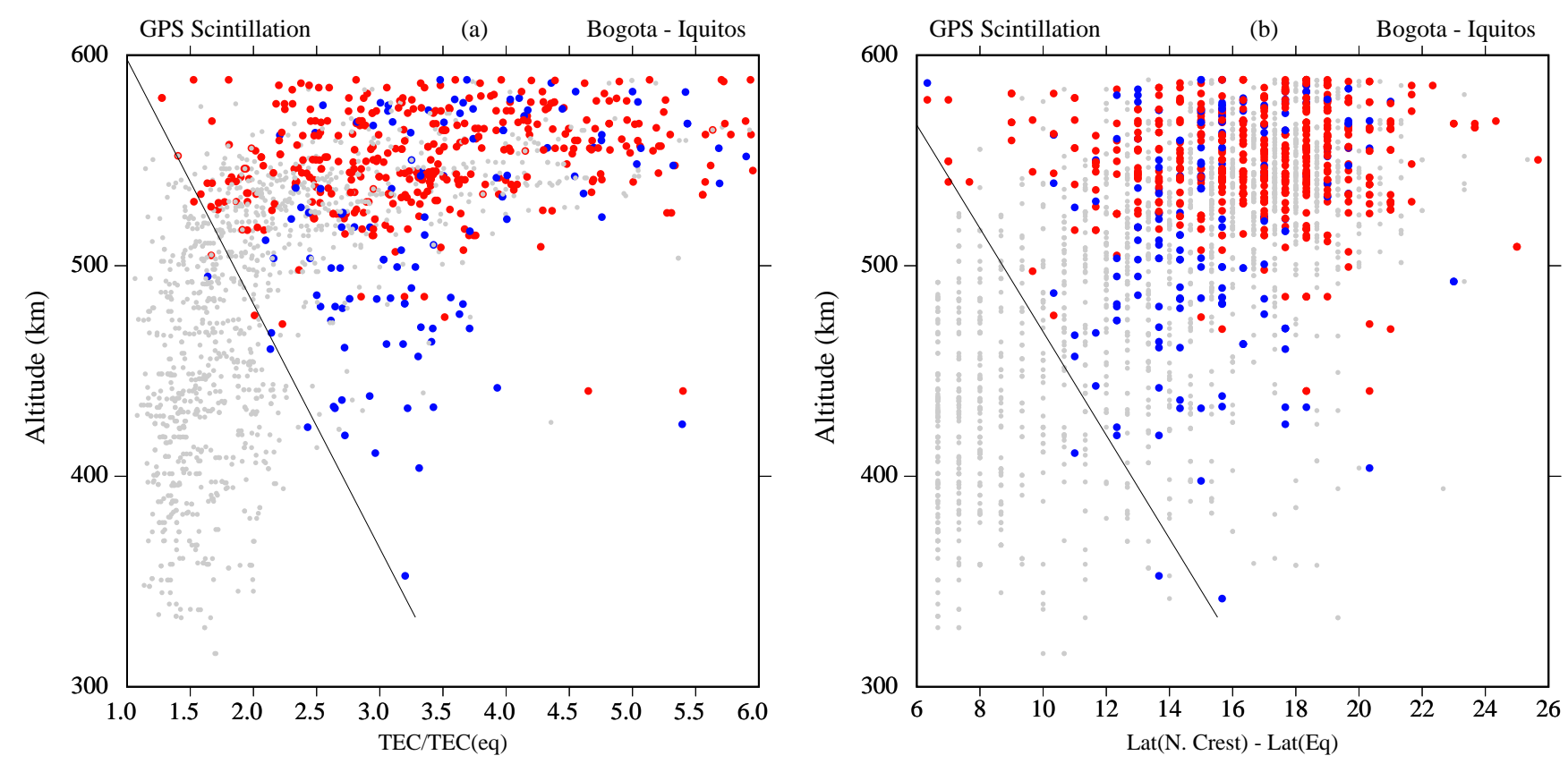

Fig. 12. Distribution of the $h m \mathrm{~F} 2$ values as a function of the crest-to-trough ratio (panel (a) and vs. the crest separation (panel (b)), binned according to the presence (colored dots) and absence of GPS scintillations (gray dots). The inclined lines in the left part of each frame have been fitted to the minimum values of the crest/trough ratio (or crest separations) for different altitude sectors.

signal from the same GPS satellite is recorded at different stations. One of the physical properties inferred from the TEC data is the determination of the location where a bubble is triggered. Figures $3 \mathrm{a}, 3 \mathrm{~b}$ and $3 \mathrm{e}$ (corresponding to Bogota, Iquitos and Cuzco) observed 2 TEC depletions between 19:00 and 22:00 LT; contrary to this, Figs. $3 \mathrm{c}$ and $3 \mathrm{~d}$ (Pucallpa and Ancon) showed only one depletion. This fact indicated that the TEC depletion seen at Iquitos between 20:20 and 20:42 LT, which was also observed in Bogota between 20:30 and 20:53 LT, most likely originated in a location between Pucallpa and Iquitos. The depletion seen at Pucallpa between 21:08 and 21:47 LT could not be associated with the plasma bubble recorded much earlier at Iquitos and Bogota since the plasma depletions were drifting eastward. The average drift of the background plasma is another physical parameter that can be calculated using the arrival time of the TEC depletion as it moves from one station to another located further east. TEC observations from 2 stations located near the magnetic equator such as Ancon and Cuzco (Figs. 2c and 2d) show the passage of a TEC depletion crossing their ionospheric intersections with relatively small changes in the shape of the depletion. We determined a velocity equal to $140 \mathrm{~m} / \mathrm{s}$ using the time elapsed between the TEC minima at Ancon and Cuzco and the east-west distance between the stations. In agreement with this value, the UHF spaced-receiver scintillation system that operates at Ancon (Valladares et al., 1996) measured a zonal drift equal to $160 \mathrm{~m} / \mathrm{s}$ at $22: 10 \mathrm{LT}$. The third geophysical parameter that we calculated was the westward tilt of the plasma bubbles. Comparison of the TEC curves measured at Cuzco, Iquitos and Bogota indicated the passage of a TEC depletion at times that were consistent with plumes tilted westward at higher altitudes. We observed that the flux tubes that extended to larger magnetic latitudes (Bogota) lagged the flux tubes that ended closer to the equator (Cuzco). On both days the TEC depletions were observed almost overhead the sites. The tilt angles were calculated using precise estimates of the time and location of a TEC depletion detected at Bogota, an off equatorial site, and the time and location when the same depletion was observed at Cuzco or Arequipa, both near-equatorial stations. A zonal drift equal to $140 \mathrm{~m} / \mathrm{s}$ was used on both days to "transport" the location of the TEC depletion to a common observational time. These locations were then mapped using the IGRF model of the magnetic field to determine their separation in altitude and the east-west distance. A tilt angle equal to $20^{\circ}$ was observed on 7 September 2001 and $25^{\circ}$ on 6 February 2002. These values are in accord with tilt angles recently calculated by Makela and Kelley (2003) using airglow images of plasma depletions recorded at Hawaii. Woodman and LaHoz (1976) suggested that an altitude-sheared zonal drift of the ionosphere or a slip velocity between the neutrals and ionized medium could cause the tilt of the radar plumes. The numerical simulations of Zalesak et al. (1982) indicated that the westward tilt of the plumes was attributed to an incomplete coupling of the plasma motion to the neutral wind due to a finite conductivity of the $\mathrm{E}$ layer away from the equator.

We observed that at Bogota, which is typically located under the crest, both walls of the TEC depletions commonly presented intense levels of GPS scintillations. At Cuzco and Iquitos, the GPS scintillations were mainly restricted to the west side of the plasma bubbles. The latter can be understood in terms of the gradient-drift instability, which is able 
to generate irregularities on the west wall of a plasma bubble. A zonal neutral wind $\mathbf{U}$ is also able to produce structures under the condition $\mathbf{U} \cdot \nabla n<0$, which for an eastward wind corresponds again to the westward wall. Based on their computer calculations Zalesak et al. (1982) indicated that the westward as well as the eastward wall could be subject to secondary instabilities. These authors included the tilt of the plumes and suggested that at high altitudes the normally stable east wall orients out of the purely vertical direction and becomes unstable to the gravitational and gradient-drift instabilities. More refined statistical analysis of these geophysical parameters will be exploited in the future to investigate the evolution and lifetime of the plasma bubbles and their associated scintillations.

By using data collected by the JULIA radar, along with TEC and GPS scintillations, we have constructed a very complete diagnostic of the background and the turbulent state of the nighttime low-latitude ionosphere for three different days. The radar coherent echoes, TEC depletions, GPS scintillations, and the TEC latitudinal profiles of Figs. 4, 5, and 6 portray the seasonal and day-to-day variability of the equatorial irregularities at different scale sizes. The following features were consistently observed in all three figures:

1) The location and the depth of the TEC depletions were approximately symmetric with respect to the magnetic equator, even when the background TEC was not symmetric. The absence of GPS scintillation measurements south the magnetic equator prevented us from investigating the symmetry of this parameter. 2) The depth of the TEC depletions and the intensity of GPS scintillations were larger at the crests of the anomaly than at the trough. 3) The latitudinal extension of the locations of the TEC depletions was equal to the extension of GPS scintillations. 4) Radar plumes were always collocated with TEC depletions and GPS scintillations. In addition, when the JULIA radar observed bottomside traces, these were not observed to be associated with GPS scintillations. The latter two experimental facts reaffirm the theoretical predictions of Costa and Kelley (1976) and previous observations conducted by Basu et al. (1986). The presence of the largest depletion depths at the crests of the anomaly is probably a consequence of the density along the depleted flux tubes being almost constant (Hanson and Bamgboye, 1984). Because the background undisturbed density is the largest at the crests, then a more dense region will be evacuated by the instability process, resulting in a much deeper depletion. Recently, Keskinen et al. (2003) have studied the three-dimensional nonlinear evolution of plasma bubbles and demonstrated that the sharpest density gradients exist at equatorial anomaly latitudes. We found that indeed GPS scintillations were more prominent near the crest, but when a single station was considered, we found no firm assurance that deeper TEC depletions correlate with more intense GPS scintillations. In fact, by comparing Figs. 4 and 5 the opposite correspondence seems to be valid. Figure 2 shows a 20-unit depletion that was observed at Cuzco on 7 September 2001. This depletion was accompanied with a S4 index near the noise level (0.20). In comparison, a smaller 12-unit depletion was seen on 3 December 2001, but on this day the GPS scintillations exceeded 0.3. LaBelle and Kelley (1986) have presented the spatial spectrum of irregularities, detected by two rockets launched into ESF, that exhibited a knee near the 1-km scale length. These authors suggested that two processes could affect the amplitude of km-scale irregularities: 1) the injection of $\mathrm{km}$-scale turbulence at the steepened walls of plasma bubbles and 2) nonlocal effects of the underlying E region. While it is likely that density gradients with scale lengths of the order of a few hundred meters exist at the walls of the plasma bubbles, electric fields with these dimensions do not easily map to the E-region (Farley, 1960). In principle, the depth and width of TEC depletions, and also the TEC gradients within the TEC depletions, do not necessarily reflect the sharpness of the density gradients in the F-region, as TEC is an integrated measurement that heavily depends upon the satellite elevation, the tilt of the plasma bubbles, the zonal plasma drift, and even the satellite trajectory. Contrary to the uncertain relationship between TEC depletions and GPS scintillations, we observed that the intensity of coherent echoes seem to follow a proportional relationship with the depth of the TEC depletions. Figures 4, 5 and 6 suggested that the intensity of the coherent echoes recorded by the JULIA radar followed a proportional dependence with the depth of the TEC depletions. As a corollary, we state the lack of a proportional correspondence between the level of the GPS $(1.6 \mathrm{GHz})$ scintillations and the intensity of the coherent echoes recorded by the JULIA radar. At $1.6 \mathrm{GHz}$, scintillations are caused by irregularities in the range $40-400 \mathrm{~m}$ in dimension. Therefore, we should not expect a one-to-one relationship with the $50 \mathrm{MHz}$ backscatter, which is caused by $3-\mathrm{m}$ irregularities. The different frames of Fig. 7 have illustrated the direct relationship that exists between the location and width of the crests and the latitudinal extension of the region where GPS scintillations (400-m scale length structures) occur. For 10 days (Fig. 7) scintillations were confined within the limits of the equatorial anomaly. This particular association can be understood by invoking the arguments employed by Sultan (1996) to derive the non-local linear growth rate of the RTI. This author used the magnetic flux tube formalism of Haerendel (1973) to numerically calculate the RTI growth rate, taking into account changes in physical parameters over the entire magnetic field tube. The flux-tube integrated parameters presented by Sultan (1996) showed the integrated Pedersen conductivity increasing up to $1000 \mathrm{~km}$ altitude and growth rates remaining positive even at $800 \mathrm{~km}$. Under these circumstances, one expects to find radar plumes reaching the topside, or altitudes near $800 \mathrm{~km}$. Field lines that cross the equatorial topside are unstable to the RTI because of the longer length of flux tubes that penetrate the crests of the anomaly and the much higher TEC and F-region density at the F-region ends of these field lines. Field lines with higher apex altitudes are even longer but will end poleward of the crests where the density is much reduced. On two other days, 10 February 2002 and 18 December 2001, GPS scintillations were observed at latitudes one or two degrees beyond the northern boundary of the anomaly. However, we 
noticed that on these two days, the southern crest reached more poleward latitudes than the northern peak. This again reinforces the need to conduct the field line integration from end-to-end of the flux tube. We suggest that this relationship between the latitudinal width of the anomaly and the extension of GPS scintillations seems to be necessary conditions for all local times, all magnetic conditions, and probably all solar activity epochs. The bottom row of Fig. 7 has shown the TEC distributions for 3 days when no GPS scintillations were detected. The common feature on all 3 days was the large TEC value ( $>75$ units) at the trough and the crest/trough ratio less than 2 . This behavior of a stable equatorial ionosphere is in agreement with the conditions of the TEC profiles put forth by Valladares et al. (2001). Figure 7 also introduced the role of the reverse fountain effect, acting as a suppressor of plasma bubbles and GPS scintillations. The initiation of the reverse fountain was illustrated in Figure $4 \mathrm{a}$ in which a bottomside trace was observed to be moving rapidly downward after 19:30 UT. Simultaneously, the TEC latitudinal profiles indicated an increase in the TEC values near the magnetic equator. We have observed that GPS scintillations can be inhibited right after the start of the reverse fountain effect; but can also decay $1-2 \mathrm{~h}$ afterwards. Below we explain how the re-distribution of plasma along the field lines can make the equatorial ionosphere become stable to the RTI and are able to suppress or extinguish ESF irregularities. We did not expect to find the strong asymmetry of the TEC profiles that prevailed during the December solstice, even during days when the latitudinal distribution of the TEC depletions was symmetric with respect to the magnetic equator. On many days, GPS scintillations, TEC depletions, and radar plumes were detected even when the southern crest was absent. The main contributor to the asymmetry of the anomaly is the meridional wind that during the December solstice blows from south to north (Walker et al., 1994). Other factors may be an asymmetrical distribution of the $\mathrm{O} / \mathrm{N} 2$ ratio or latitudinal gradients of the zonal or vertical neutral wind.

Figures 8 and 9 indicated that sometimes GPS scintillations could be detected poleward of the $50 \%$ decay of the northern crest. In fact, a total of 9 cases were found during the analysis of this limited data set. We noticed that during these nine days the poleward boundary of the southern crest was displaced to even higher magnetic latitudes than the poleward boundary of the northern crest. This will definitely augment the flux-tube integrated conductivity of the field line that intersects the poleward boundary of the GPS scintillations. In summary, Figs. 7, 8 and 9 reaffirm that the stability of the flux tube is a non-local phenomenon that depends on the density along the whole flux tube.

Figure 12 indicated that when the equatorial F-region peak is above $500 \mathrm{~km}$, the low-latitude ionosphere is inherently unstable to the onset of the RTI. Then, if gravity waves (Kelley et al., 1981; Hysell et al., 1990) are present, GPS scintillations and plasma bubbles will develop. But as the F-region descends toward lower apex altitudes, the requirement for ESF turbulence becomes more stringent, and larger crest/trough TEC ratios and more widely separated crests are needed for the ionosphere to remain unstable. Figure 13 presents the schematic representations of the ionospheric densities for two different scenarios in which the nighttime F-region can be considered disturbed. These plots display a north-south $36^{\circ}$-segment of the equatorial ionosphere centered at the magnetic equator. Four field lines with apex altitudes varying from $500 \mathrm{~km}$ to $2000 \mathrm{~km}$ are indicated in each of the two frames. Both plots have been properly scaled to depict horizontal and vertical distances proportionally. The circular segment near the lower boundary represents the surface of the Earth. The numbers under this curve show the geographic latitude at the $76^{\circ} \mathrm{W}$ meridian. The main differences between these two frames are the altitude of the Fregion at the magnetic equator and the poleward extension of the anomaly. The left frame shows a density distribution that contains an equatorial F-region peaking at $750 \mathrm{~km}$ altitude and the crests separated by $8^{\circ}$ from the magnetic equator. The right frame displays the F-region $h m \mathrm{~F} 2$ at $400 \mathrm{~km}$ altitude, and the anomaly extending up to $15^{\circ}$. Although the latitude-altitude profiles of Fig. 13 look drastically different, their flux-tube integrated parameters, such as conductivities, density gradients, and probably their growth rates, will have a much closer resemblance. We suggest that both density distributions presented in Fig. 13 will be conducive to the development of ESF, favor the initiation of plasma bubbles and support the persistence of bubbles and GPS scintillations. However, we note that the larger latitudinal extension of the density distribution of the right frame will support taller plumes and GPS scintillations incursions to much higher latitudes. When the crest/trough ratio decreases, the crest separation becomes either small, or the peak altitude of the equatorial F-region reduces, thus the plasma depletions will be annihilated. The reverse fountain effect is a plasma redistribution process in which crest plasma is transported toward the magnetic equator due to pressure gradients along the field lines that are large enough to overcome the gravity force. The main driver of the reverse fountain is the downward motion of the plasma at equatorial latitudes. Previous studies that have used DMSP data (Sultan and Rich, 2000; Huang et al., 2001) concluded that the amplitude of the crest is associated with the occurrence pattern of ESF. Here, we have demonstrated that the crest/trough ratio, the crest separation, together with the altitude of the equatorial F-region, are the parameters that can be used to forecast the onset, the persistence, and the maximum altitude of the plasma plumes.

As final remarks we point out that it is conceivable that the proper conditions for bubble generation could be set, in some circumstances, even hours prior to sunset (e.g. a large daytime vertical drift). When this happens plasma bubbles would be triggered just after the decay of the underlying $\mathrm{E}$ region. During these events, it would be possible to define precursors of the ESF, as has been indicated by Raghavarao et al. (1988). We are aware that the TEC is an integrated quantity equal to the integral of the density between the lower boundary of the $\mathrm{D}$ region and the satellite altitude. As such, it does not reproduce all the variability of the density profiles. 

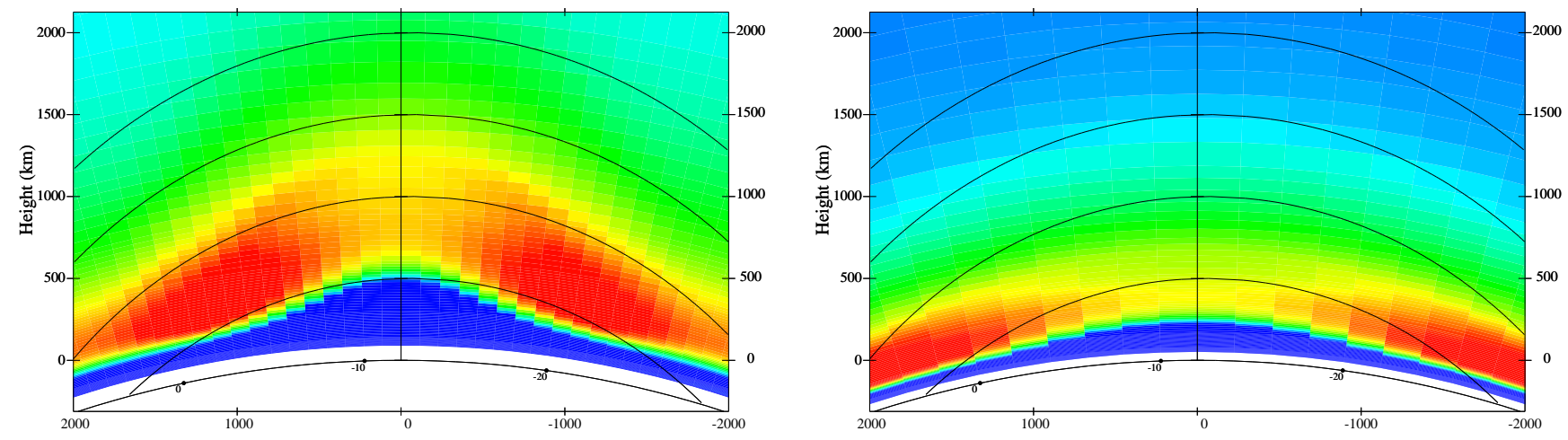

Fig. 13. Schematic representation showing two possible scenarios of the latitudinal distribution of the F-region densities during events that support the initiation and the development of plasma depletions. Note the difference in the altitude of the F-region near the magnetic equator and the locations of the Anomaly crests.

Nevertheless, after sunset the F-layer is reduced in depth and the TEC becomes a good representation of the density. We emphasize that the three parameters mentioned above can be used as a proxy for the initiation and persistence of equatorial plasma bubbles.

\section{Conclusions}

The investigation has led to the following:

1. We have shown that independent measurements of the same TEC depletion by two GPS receivers displaced in longitude can be employed to estimate the eastward motion of the background ionosphere. GPS receivers displaced in latitude can also provide the tilt of the plasma plumes. We demonstrated that in some instances GPS receivers indicate the place and time of bubble initiation.

2. The three case-study events presented here have demonstrated the temporal and spatial correspondence between radar plumes, GPS scintillations and TEC depletions. This fact supports the use of several GPS receiver sites to monitor the maximum altitude of the plasma bubbles.

3. We did not find a direct relationship between the depth of the TEC depletion and the intensity of GPS scintillations. Nevertheless, more intense coherent echoes were observed when deeper TEC depletions transited above the JULIA radar.

4. At Bogota, GPS scintillations were seen on both walls of the TEC depletions. At Iquitos and Cuzco scintillations mainly occurred in the west side of the depletions. This latitudinal distribution of scintillations is in accord with predictions presented by Zalesak et al. (1982) based on numerical simulations of the evolution of plasma bubbles.
5. We detected strong levels of GPS scintillation and deep TEC depletions when the TEC latitudinal profiles were symmetric, asymmetric, or even when one of the crests was absent. This fact indicates the importance of fluxtube integrated quantities to assess the stability of the equatorial F-region (Sultan, 1996).

6. There exists a prominent day-to-day variability in the location and width of the crest. The trough is principally located near the magnetic equator, but it contains a $2^{\circ}$ dispersion with respect to the equator. The crests locations typically vary between $10^{\circ}$ and $18^{\circ}$ of magnetic latitude, but could be as small as $5^{\circ}$ from the magnetic equator.

7. The poleward boundary of GPS scintillations and TEC depletions were bounded $90 \%$ of the days to the regions where the equatorial anomaly decreased $50 \%$ of the peak value. Weak level of scintillations were seen near the trough, but much higher values $(>0.8)$ were observed at the crests during this period of solar maximum conditions.

8. In agreement with previous studies of the onset of ESF phenomena, we found that the majority of scintillation events start when the F-layer peak was above $500 \mathrm{~km}$. We observed that scintillations and TEC depletions can persist during the descending phase of the F-region, but rapidly decay when the F-region peak is below $300 \mathrm{~km}$ altitude. TEC latitudinal profiles obtained simultaneously during scintillation events and equatorial F-region peak altitudes below $500 \mathrm{~km}$ indicate that these events occur when the crest-to-trough TEC ratios are larger than 2.2; and the crest separation is $10^{\circ}$ or more. These limits apply to the onset as well as the persistence of GPS scintillations. This result is largely unexpected, as the persistence of GPS scintillations is mainly dominated by the electrical and magnetic properties of the plasma bubble. 
9. The good correlation between the appearance of the reverse fountain and the inhibition of scintillations can be understood in terms of the redistribution of the plasma along the field lines, flowing from the crest toward the magnetic equator and then to lower altitudes. The development of the reverse fountain effect implies a decrease in the crest/trough TEC ratio and a reduction in the crest separation. We postulate that these two facts make the whole flux-tube more stable to the RTI.

10. We conclude that tracking the location, magnitude and extension of both crests of the anomaly can serve to infer the maximum latitudinal extension of scintillations, TEC depletions, and the maximum altitude of radar plumes. Precise measurements of TEC latitudinal profiles and bottomside density profiles can be used to predict the onset of plasma bubbles and to infer the evolution and decay time of the ESF phenomenon.

Acknowledgements. The authors would like to thank A. Mazzella of the Northwest Research Associates for allowing us to use the SCORE program, which was instrumental in the success of this study. M. Bevis and E. Kendrick of the University of Hawaii provided data from their Iquique, Copiapo, and Antuco stations; these stations are part of the South Andes Project (SAP). We are grateful to T. Bullett for his helpful comments and suggestions on the paper. We thank J. Espinoza and R. Villafani for their dedication to the smooth operation of the spaced receiver scintillation instrument at Ancon, Peru. This material is based upon work supported by the NSF under Grants 0123560 and 0243294 . The work at Boston College was also partially supported by Air Force Research Laboratory contract F19628-02-C-0087, AFOSR task 2311AS. The observatory of Ancon is operated by the Geophysical Institute of Peru, Ministry of Education. The Jicamarca Radio Observatory is operated by the Geophysical Institute of Peru, Ministry of Education, with support from the National Science Foundation Cooperative Agreement ATM-9911209 through Cornell University.

Topical Editor M. Lester thanks two referees for their help in evaluating this paper.

\section{References}

Balan, N. and Bailey, G. J.: Equatorial plasma fountain and its effects: Possibility of an additional layer, J. Geophys. Res., 100, $21421,1995$.

Basu, S., Basu, S., LaBelle, J., Kudeki, E., Fejer, B. G., Kelley, M. C., Whitney, H. E., and Bushby, A.: Gigahertz scintillations and spaced receiver drift measurements during Project Condor equatorial F-region rocket campaign in Peru, J. Geophys. Res., 91, 5526, 1986.

Basu, S., E. Kudeki, Basu, Su., et al.: Scintillations, plasma drifts, and neutral winds in the equatorial ionosphere after sunset, J. Geophys. Res., 101, 26 795, 1996.

Costa, E. and Kelley, M. C.: Calculations of equatorial scintillations at VHF gigahertz frequencies based on a new model of the disturbed equatorial ionosphere, Geophys. Res. Lett., 3, 677, 1976.

DasGupta, A., Basu, S., Aarons, J., Klobuchar, J. A., Basu, S., and Bushby, A.: VHF amplitude scintillations and associated electron content depletions as observed at Arequipa, Peru, J. Atm. Terr. Phys., 45, 15, 1983.
Devasia, C. V., Jyoti, N., Subbarao, K. S. V., Viswanathan, K. S., Tiwari, D., and Sridharan, R.: On the plausible linkage of thermospheric meridional winds with the equatorial spread F, J. Atm. and Sol. Terr. Phys., 64, 111, 2002.

Eccles, J. V.: Modeling investigation of the evening prereversal enhancement of the zonal electric field in the equatorial ionosphere, J. Geophys. Res., 103, 26709, 1998.

Farley, D. T.: A theory of electrostatic fields in the ionosphere at nonpolar geomagnetic latitudes, J. Geophys. Res., 65, 869, 1960.

Farley, D. T., Bonnelli, E., Fejer, B. G., and Larsen, M. F.: The prereversal enhancement of the zonal electric field in the equatorial ionosphere, J. Geophys. Res., 91, 13 723, 1986.

Fejer, B .G., Scherliess, L., and de Paula, E. R.: Effects of the vertical plasma drift velocity on the generation and evolution of equatorial spread F, J. Geophys. Res., 104, 19 859-19869, 1999.

Haerendel, G.: Theory of equatorial spread F, unpublished report, Max Planck Instit für Extraterr. Phys., 1973.

Haerendel, G. and Eccles, J. V.: The role of the equatorial electrojet in the evening ionosphere, J. Geophys. Res., 97, 1181, 1992.

Hanson, W. B. and Moffett, R. J.: Ionization transport effects in the equatorial F-region J. Geophys. Res., 71, 5559, 1966.

Hanson, W. B. and Bamgboye, D. K.: The measured motions inside equatorial plasma bubbles, J. Geophys. Res., 89, 8997, 1984.

Huang, C. Y., Burke, W. J., Machuzak, J. S., Gentile, L. C., and Sultan, P. J.: DMSP observations of equatorial plasma bubbles in the topside ionosphere near solar maximum, J. Geophys. Res., 106, 8131, 2001.

Hysell, D. L., Kelley, M. C., Swartz, W. E., and Woodman, R. F.: Seeding and layering of equatorial spread $\mathrm{F}$ by gravity waves, J. Geophys. Res., 95, 17 253, 1990.

Hysell, D. L. and Burcham, J. D.: JULIA radar studies of equatorial spread F, J. Geophys. Res., 103, 29 155, 1998.

Kelley, M. C., Larsen, M. F., LaHoz, C. A., and McClure, J. P.: Gravity wave initiation of equatorial spread F, J. Geophys. Res., 86, 9087, 1981.

Keskinen, M. J., Ossakov, S. L., and Fejer, B. G.: Threedimensional nonlinear evolution of equatorial ionospheric spread-F bubbles, Geophys. Res. Lett., 30, doi:10.1029/2003GL17418, 1855, 2003.

LaBelle, J., and Kelley, M. C.: The generation of kilometer scale irregularities in equatorial spread F, J. Geophys. Res., 91, 5504, 1986.

Makela, J. J. and Kelley, M. C.: Field-aligned 777.4 nm composition airglow images of equatorial plasma depletions, Geophys. Res. Lett., 30, doi:10.1029/2003GL17106, 1442, 2003.

Maruyama, T.: A diagnostic model for equatorial spread F, 1. Model description and application to electric field and neutral wind effects, J. Geophys. Res., 93, 14 611, 1988.

Maruyama, T. and Matuura, N.: Longitudinal variability of annual changes in activity of equatorial spread $\mathrm{F}$ and plasma bubbles, $\mathrm{J}$. Geophys. Res., 89, 10 903, 1984.

McClure, J. P., Hanson, W. B., and Hoffman, J. H.: Plasma bubbles and irregularities in the equatorial ionosphere, J. Geophys. Res., 82, $2650,1977$.

Mendillo, M., Baumgardner, J., Pi, X., Sultan, P. J., and Tsunoda, R.: Onset conditions for equatorial spread $F$, J. Geophys. Res., 97, $13865,1992$.

Mendillo, M., Meriwether, J., and Biondi, M.: Testing the thermospheric neutral wind suppression mechanism for day-to-day variability of equatorial spread F, J. Geophys. Res., 106, 3655, 2001.

Meriwether, J. W., Moody, J. W., Biondi, M. A., and Roble, R. 
G.: Optical interferometric measurements of nighttime equatorial thermospheric winds at Arequipa, Peru, J. Geophys. Res., 91, 5557, 1986.

Ossakow, S. L., Zalesak, S. T., McDonald, B. E., and Chaturvedi, P. K.: Nonlinear equatorial spread- $F$ : Dependence on altitude of the $F$ peak and bottomside background electron density gradient scale length, J. Geophys. Res., 84, 17, 1979.

Ott, E.: Theory of Rayleigh-Taylor bubbles in the equatorial ionosphere, J. Geophys. Res., 83, 2066, 1978.

Raghavarao, R., Nageshwararao, M., Hanumath Sastri, J., Vyas, G. D., and Sriramarao, M.: Role of equatorial ionization anomaly in the initiation of equatorial spread- $F$, J. Geophys. Res., 93, 5959, 1988.

Satyanarayana, P., Guzdar, P. N., Huba, J. D., and Ossakow, S. L.: Rayleigh-Taylor instability in the presence of a stratified shear layer, J. Geophys. Res., 89, 2945, 1984.

Sridharan, R., Sekar, R., and Gurubaran, S.: Two-dimensional highresolution imaging of the equatorial plasma fountain, J. Atm. and Terr. Phys., 55, 1661, 1993.

Sridharan, R., PallamRaju, D., Raghavarao, R., and Ramarao, P. V. S.: Precursor to equatorial spread- $F$ in OI $630.0 \mathrm{~nm}$ dayglow, Geophys. Res. Lett., 21, 2797, 1994.

Sultan, P.: Linear theory and modeling of the Rayleigh-Taylor instability leading to the occurrence of equatorial spread F, J. Geophys. Res., 101, 26875, 1996.

Sultan, P. J. and Rich, F. I.: Observations and modeling of the seasonal and longitudinal occurrence pattern of equatorial spread$F$, paper presented at Chapman Conference on Space Weather: Progress and Challenges in Research and Applications, AGU, Clearwater, Fla., March 2000.
Valladares, C. E., Sheehan, R., Basu, S., Kuenzler, H., and Espinoza, J.: The multi-instrumented studies of equatorial thermosphere aeronomy scintillation system: Climatology of zonal drifts, J. Geophys. Res., 101, 26 839-26 850, 1996.

Valladares, C. E., Basu, S., Groves, K., Hagan, M. P., Hysell, D., Mazzella Jr., A. J., and Sheehan, R. E.: Measurement of the latitudinal distributions of total electron content during equatorial spread-F events, J. Geophys. Res., 106, 29 133, 2001.

Walker, G. O., Ma, J. H. K., and Golton, E.: The equatorial ionospheric anomaly in electron content from solar minimum for South East Asia, Ann. Geophys., 12, 195, 1994.

Weber, E. J., Basu, S., Bullett, T. W., et al.: Equatorial plasma depletion precursor signatures and onset observed at $11^{\circ}$ south of the magnetic equator, J. Geophys. Res., 101, $26829,1996$.

Whalen, J. A.: The equatorial anomaly: Its quantitative relation to equatorial bubbles, bottomside spread F, and $\boldsymbol{E} \times \boldsymbol{B}$ drift velocity during a month at solar maximum, J. Geophys. Res., 106, 29 125, 2001.

Woodman, R. F.: Vertical drift velocities and east-west electric fields at the magnetic equator, J. Geophys. Res., 75, 6249, 1970.

Woodman, R. F. and LaHoz, C.: Radar observations of $F$ region equatorial irregularities, J. Geophys. Res., 81, 5447, 1976.

Zalesak, S. T. and Ossakow, S. L.: Nonlinear equatorial spread $F$ : Spatially large bubbles resulting from large horizontal scale initial perturbations, J. Geophys. Res., 85, 2131, 1980.

Zalesak, S. T., Ossakow, S. L., and Chaturvedi, P. K.: Nonlinear equatorial spread F: The effect of neutral winds and background Pedersen conductivity, J. Geophys. Res., 87, 151, 1982.

Zargham, S. and Seyler, C. E.: Collisional interchange instability, 1, Numerical simulations of intermediate-scale irregularities, J. Geophys. Res., 92, $10073,1987$. 